OPEN ACCESS

Edited by: Michael Nevels, University of Regensburg, Germany

Reviewed by: Charles Grose, University of lowa, USA Lin Deng,

Kobe University Graduate School of Medicine, Japan

*Correspondence:

Subhash C. Verma scverma@medicine.nevada.edu

Specialty section: This article was submitted to Virology,

a section of the journal Frontiers in Microbiology

Received: 28 February 2016

Accepted: 11 April 2016

Published: 27 April 2016

Citation:

Banerjee S, Uppal T, Strahan R, Dabral P and Verma SC (2016)

The Modulation of Apoptotic Pathways by Gammaherpesviruses.

Front. Microbiol. 7:585 doi: 10.3389/fmicb.2016.00585

\section{The Modulation of Apoptotic Pathways by Gammaherpesviruses}

\author{
Shuvomoy Banerjee', Timsy Uppal2, Roxanne Strahan ${ }^{2}$, Prerna Dabral' ${ }^{2}$ and \\ Subhash C. Verma ${ }^{2 *}$ \\ ${ }^{1}$ Amity Institute of Virology and Immunology, Amity University, Noida, India, ${ }^{2}$ Department of Microbiology and Immunology, \\ Center for Molecular Medicine, School of Medicine, University of Nevada, Reno, Reno, NV, USA
}

Apoptosis or programmed cell death is a tightly regulated process fundamental for cellular development and elimination of damaged or infected cells during the maintenance of cellular homeostasis. It is also an important cellular defense mechanism against viral invasion. In many instances, abnormal regulation of apoptosis has been associated with a number of diseases, including cancer development. Following infection of host cells, persistent and oncogenic viruses such as the members of the Gammaherpesvirus family employ a number of different mechanisms to avoid the host cell's "burglar" alarm and to alter the extrinsic and intrinsic apoptotic pathways by either deregulating the expressions of cellular signaling genes or by encoding the viral homologs of cellular genes. In this review, we summarize the recent findings on how gammaherpesviruses inhibit cellular apoptosis via virus-encoded proteins by mediating modification of numerous signal transduction pathways. We also list the key viral antiapoptotic proteins that could be exploited as effective targets for novel antiviral therapies in order to stimulate apoptosis in different types of cancer cells.

\section{Keywords: apoptosis, EBV, KSHV, cancer, autophagy, LANA, EBNA3C}

\section{INTRODUCTION}

\section{Cancer and Apoptosis}

Cancer progression can be considered as mechanistically complex process with a plethora of fundamental genetic grounds. Neoplasia, i.e., abnormal growth of cells, involves multiple steps that occur gradually, starting with primary driver mutations and finally leading to tumorigenesis. During these transitional changes, cancer cells accumulate several genetic alterations that confer on the cells, an unwarranted survival and uncontrolled proliferative advantage. During development, cancer cells also encounter a physiologically ubiquitous cellular process, i.e., apoptosis or programmed cell death that eliminates the infected, damaged or abnormal cells. Therefore, it is quintessential for tumor cells to acquire counter-strategies to evade cellular apoptosis that helps to safeguard the genomic integrity (Fernald and Kurokawa, 2013). Defective and inefficient cell death, in turn, facilitates cancer development and metastasis and renders the cancer cells resistant to treatment (Brown and Attardi, 2005).

\section{Hallmarks of Apoptosis Morphological hallmarks}

The cells undergoing apoptosis display typical morphological and biochemical features. The morphological alterations in apoptosis concerning both the nucleus and the cytoplasm are 
remarkably similar across various cell types and species (Saraste and Pulkki, 2000). Morphological hallmarks of apoptosis in the nucleus are chromatin condensation, nuclear fragmentation, subsequent rounding up of the cell, pyknosis, and retraction of pseudopodes (Kroemer et al., 2005). The chromatin condensation initiates at the periphery of the nuclear membrane and forms a crescent or ring-like structure and continues until it breaks up inside a cell with an intact membrane, a feature, defined as karyorrhexis (Majno and Joris, 1995). Morphological features for late stage of apoptosis include membrane blebbing, ultrastructural modification of cytoplasmic organelles and a loss of membrane integrity (Kroemer et al., 2005). Several studies demonstrated that proteolytic cleavages of a group of cellular proteins including, actin, spectrin, gelsolin, b-catenin, PAK2, Gas2, MEKK1 by activated caspases play major role for accomplishing the morphological changes during apoptosis (Martin and Green, 1995). Enhanced expression of the caspase cleaved forms of Gas2 or gelsolin were observed for significant change in the cell morphology, resembling apoptosis (Kothakota et al., 1997). Interestingly, experimental evidences showed calpain proteases (Brown et al., 1997) to be associated with the alterations in the cytoskeleton structure during apoptosis (Saraste and Pulkki, 2000).

\section{Biochemical hallmarks}

Some of the major biochemical changes that can be observed in apoptosis include, activation of caspases, DNA and protein breakdown, membrane changes and recognition by phagocytic cells (Hengartner, 2000). In early stage of apoptosis, the expression of phosphatidylserine (PS) is observed in the outer layers of the cell membrane, which are "flipped out" from the inner layers. This phenomena permits early recognition and phagocytosis of dead cells by macrophages without the release of pro-inflammatory cellular components (Hengartner, 2001). A characteristic breakdown of DNA by endonucleases then results in large $50-300 \mathrm{~kb}$ fragments. Inter-nucleosomal cleavage of DNA into oligonucleosomal pieces of 180 to 200 base pairs has been noticed in the later stage of apoptosis (Vaux and Silke, 2003). In particular, generation of free $3^{\prime}$-hydroxyl termini on DNA via cleavage of chromatin into single as well as multiple oligonucleosome-length fragments was considered as one of the major biochemical hallmarks of apoptosis (Loo, 2011). Although this characteristic feature of apoptosis is not very specific as the typical DNA ladder in agarose gel electrophoresis can be observed in case of necrotic cells as well (McCarthy and Evan, 1998). Another striking feature of apoptosis is the activation of a group of enzymes belonging to the cysteine protease family named caspases (Hengartner, 2000). Caspases activation leads to the cleavage of vital cellular proteins and breakdown of the nuclear scaffold and cytoskeleton. Additionally, they activate DNAse, which then promotes the degradation of nuclear DNA (Lavrik I.N. et al., 2005).

\section{Apoptosis Signal Pathways}

It has been well reported that functional activation of caspases play a crucial role in apoptosis in mammalian system (Fritz et al., 2006). Caspases can be activated by either of the two known apoptotic signaling pathways, i.e., intrinsic (mitochondriamediated) and extrinsic (death receptor-mediated) pathways. Both these pathways ultimately converge to a final common pathway involving the activation of caspases that triggers the execution of apoptosis of the cell. Interestingly, there is a third, less understood intrinsic pathway, referred to as intrinsic endoplasmic reticulum (ER) pathway, which involves ER and is believed to occur in response to cellular stress (Breckenridge et al., 2003).

\section{Extrinsic or Receptor-Mediated Pathway}

The extrinsic death-receptor pathway is activated upon the death ligands binding with the death receptors (Ozoren and El-Deiry, 2003). Variety of death receptors, such as type 1 TNF receptor (TNFR1) and Fas (CD95) receptor, with their ligands, termed as TNF and Fas ligand (FasL), respectively, participate in the apoptotic pathway (Hengartner, 2001). These death receptors possess an intra-cellular death domain that recruits adapter proteins including, TNF receptor-associated death domain (TRADD), Fas-associated death domain (FADD), and caspase-8 (Schneider and Tschopp, 2000). The death ligand and the death receptor binding results in the formation of a binding site for adaptor protein, and the total ligand-receptoradaptor protein complex is considered as the death-inducing signaling complex or DISC (Wong, 2011). DISC formation initiates the assembly and activation of pro-caspase 8, which promotes apoptosis by cleaving other downstream or executioner caspases (Kruidering and Evan, 2000). Examples of other best known death receptors are DR3 (APO-3), DR4 (TNF-related apoptosis inducing ligand receptor 1 or TRAIL-1), DR5 (TRAIL2), DR 6, ectodysplasin A receptor (EDAR), and NGFR (nerve growth factor receptor; Lavrik I. et al., 2005).

\section{Intrinsic or Mitochondria-mediated Pathway}

The term "Intrinsic pathway" refers to an initiation of the apoptotic pathway within the cell as a result of several internal stimuli, including, genetic damage, oxidative stress, and hypoxia (Wong, 2011). The intrinsic pathway occurs due to the increased mitochondrial permeability and release of proapoptotic molecules, such as cytochrome-c into the cytoplasm (Danial and Korsmeyer, 2004). This pathway is also examined by a special group of proteins that belong to the $\mathrm{Bcl}-2$ family, named after the Bcl-2 gene, originally observed at the chromosomal breakpoint of the translocation of chromosome 18-14 in follicular non-Hodgkin lymphoma (Tsujimoto et al., 1984). While the anti-apoptotic group of Bcl-2 proteins (Bcl-2, Bcl-XL, Bcl-W, Bfl-1, and Mcl-1) regulates apoptosis by blocking the mitochondrial release of cytochrome-c, the pro-apoptotic proteins (Bax, Bak, Bad, Bcl-Xs, Bid, Bik, Bim, and Hrk) act by promoting this mitochondrial release of cytochrome-c. The net balance between the pro- and anti-apoptotic proteins actually determines the fate of apoptosis (Reed, 1997). Apoptosis inducing factor (AIF), second mitochondria-derived activator of caspase (Smac), direct IAP Binding protein with Low $\mathrm{pI}$ (DIABLO) and $\mathrm{Omi} /$ high temperature requirement protein $\mathrm{A}(\mathrm{HtrA} 2)$ are some of the apoptotic factors that are released from the mitochondrial inter-membrane space into the cytoplasm (Kroemer et al., 2007). 
Cytoplasmic release of cytochrome-c leads to the activation of caspase-3 via formation of apoptosome complex, that consists of, cytochrome-c, Apaf-1 and caspase-9 (Kroemer et al., 2007). Moreover, Smac/DIABLO or Omi/HtrA2 stimulates caspase activation by binding to inhibitor of apoptosis proteins (IAPs) which subsequently interferes with the interaction of IAPs and caspase-3 or -9 (LaCasse et al., 2008).

\section{Intrinsic Endoplasmic Reticulum-Mediated Pathway}

The intrinsic ER pathway is considered as the third pathway for caspase activation and supposed to be involved in caspase12-dependent and mitochondria-independent manner (Szegezdi et al., 2003). When the ER is damaged by cellular stresses, such as, hypoxia, free radicals or glucose starvation, unfolding of proteins, reduces protein synthesis and an adaptor protein known as TNF receptor associated factor 2 (TRAF2) dissociates from procaspase-12, resulting in the activation of the ER-mediated pathway (Wong, 2011).

\section{Final Pathway}

Both the intrinsic and extrinsic pathways converge to caspase3. Thereafter, caspase-3 cleaves the inhibitor of the caspaseactivated deoxyribonuclease, which is responsible for the nuclear apoptosis (Ghobrial et al., 2005). Additionally, downstream caspases induce cleavage of protein kinases, cytoskeletal proteins, DNA repair proteins and inhibitory subunits of endonuclease family and are known to influence the cellular cytoskeleton formation, cell-cycle regulation as well as signal transduction pathways which contribute to the typical morphological changes during apoptosis (Ghobrial et al., 2005).

\section{Deregulation of Apoptosis in Cancer Impaired Death Receptor Signal Transduction}

Death receptors and their ligands are the critical players in the extrinsic apoptotic pathways (Plati et al., 2011). These receptors have a death domain to attract several key molecules for inducing death signal. However, the death ligands can also bind to decoy death receptors without these death domain, as a result of which, the signaling complexes fail to initiate the signal transduction (Lavrik I. et al., 2005). Several abnormalities in the death signaling pathways have been identified, including, down-regulation of the receptor or impairment of receptor function and reduced level in the death signal (Wong, 2011). Decreased membrane expression of death receptors and anomalous expression of decoy receptors have also been reported to play a major role for evading death signaling during different malignancies (Fulda, 2010). Several studies have demonstrated that ligand and death receptor expression during different stages of cervical cancer were linked to a discrepancy between apoptosis and cellular proliferation. In particular, studies by Reesink-Peters et al. (2005) demonstrated that loss of Fas and dysregulation of FasL, DR4, DR5, and tumor necrosis factorrelated apoptosis-inducing ligand (TRAIL) in the cervical intraepithelial neoplasia (Parravicini et al., 2000) are thought to be responsible for cervical carcinogenesis (Reesink-Peters et al., 2005).

\section{Enhanced Expression of Anti-apoptotic Proteins}

The Bcl-2 family of proteins comprises of the pro-apoptotic and anti-apoptotic proteins that play an essential role in the regulation of intrinsic mitochondria-mediated apoptotic pathway (Gross et al., 1999). Interestingly, Bcl-2, encoded by the $B c l-2$ (Bcell lymphoma 2) gene was the first protein of this family to be recognized, more than 20 years ago (Tsujimoto et al., 1984). All the members of the Bcl-2 family proteins are abundantly present on the outer mitochondrial membrane, are dimers in nature and responsible for membrane permeability either in the form of an ion channel or through the formation of pores (Minn et al., 1997).

\section{Reduced Expression of Pro-apoptotic Proteins}

The group of pro-apoptotic proteins including, Bid, Bim, Puma, Noxa, Bad, Bmf, Hrk, and Bik are restricted to the $\mathrm{BH} 3$ domain. Multiple cellular stress responses resulting from DNA damage, growth factor deficiency, and ER stress, can activate the BH3only proteins. Members of this group such as, Bax, Bak, and Bok/Mtd, contain all four BH3 domains which are also proapoptotic (Wong, 2011). When there is a disturbance in the balance of anti-apoptotic and pro-apoptotic members of the $\mathrm{Bcl}-2$ family, apoptotic deregulation is triggered in the affected cells. Studies by Raffo et al. (1995) showed that overexpression of $\mathrm{Bcl}-2$ protects prostate cancer cells from apoptosis (Raffo et al., 1995) whereas, studies by Fulda et al. (2002) demonstrated that increased expression of Bcl-2 proteins lead to inhibition of TRAIL-induced apoptosis in neuroblastoma, glioblastoma, and breast carcinoma cells. Interestingly, overexpression of $\mathrm{Bcl}-\mathrm{xL}$ has been reported to confer a multi-drug resistance phenotype in tumor cells and prevent them from apoptosis (Minn et al., 1995). Mutations in the Bax gene are also very common in case of colorectal carcinogenesis with microsatellite instability. Miquel et al. (2005) concluded that impaired apoptosis resulting from bax $(\mathrm{G}) 8$ frameshift mutations are responsible for growing resistance of colorectal cancer cells to anticancer treatments. Moreover, tumor cells of chronic lymphocytic leukaemia (CLL) showed an anti-apoptotic phenotype with high levels of antiapoptotic Bcl-2 protein and low levels of pro-apoptotic Bax in vivo. Cancer progression in CLL is considered to be due to the reduced level of apoptosis rather than enhanced proliferation in vivo (Goolsby et al., 2005). Studies by Pepper et al. (1997) demonstrated an increased $\mathrm{Bcl}-2 / \mathrm{Bax}$ ratio in B-lymphocytes in CLL, both in patients and in cultured conditions. The drug induced apoptosis in these B-lymphocytes was found to be inversely related to Bcl-2/Bax ratios (Pepper et al., 1997).

\section{Dysregulated p53 Functions}

p53 is not only involved in the apoptotic induction but, it is also a vital player in cell-cycle regulation, differentiation, developmental process, gene amplification, DNA recombination, chromosomal segregation, and cellular senescence (Oren and Rotter, 1999). As a result, p53 is called as the "guardian of the genome" (Lane, 1992) and most importantly defects in the p53 tumor suppressor gene have been associated with more than 50\% of human malignancies (Sherr and McCormick, 2002). Recent studies by Avery-Kiejda et al. (2011) showed a subset of target genes of p53 involved in apoptosis and cell-cycle regulations are 
abnormally expressed in melanoma cells, leading to abnormal p53 activity and contributing to cellular proliferation. In vivo mice studies using a N-terminal deletion mutant of p53 $(\Delta 122 \mathrm{p} 53)$ corresponding to $\Delta 133 \mathrm{p} 53$ showed decreased survival rate and profound pro-inflammatory phenotype with reduced apoptosis (Slatter et al., 2011). Additionally, it has been observed that silencing of p53 mutant, followed by downregulated expression of p53 mutant resulted in low colony formation in human cancer cells with induced apoptosis (Vikhanskaya et al., 2007). In 1997, two members of p53 family were identified including, p73 (Kaghad et al., 1997) and p63 (Yang et al., 1998). Both p73 and p63 have significant structural similarity with p53 and are involved in a broad spectrum of biological activities (Collavin et al., 2010). Interestingly, several studies have demonstrated that both p63 and p73 are involved in different cellular response to cancer therapy and both of them are required for $\mathrm{p} 53$-induced apoptosis, suggesting the functional relationship among p53 family proteins (Chakraborty et al., 2010; Dotsch et al., 2010).

\section{Downregulated Caspases Activities}

The caspases are classified into two groups: (i) those related to caspase 1 (caspase-4, caspase-5, caspase-13, and caspase-14) are mostly involved in cytokine processing during inflammatory processes, and (ii) those that play vital role in apoptotic process (e.g., caspase-2, caspase-3, caspase-6, caspase-7, caspase8 , caspase-9, and caspase-10). Moreover, the second group can be further divided into initiator caspases, which are primarily responsible for the initiation of the apoptotic pathway (e.g., caspase-2, caspase-8, caspase-9, and caspase-10) and effector caspases (caspase-3, caspase-6, and caspase-7), which are accountable for the actual cleavage of cellular components during apoptosis (Fink and Cookson, 2005). Therefore, lower levels of caspases or deficiency in caspase function may cause reduced apoptosis or carcinogenesis (Wong, 2011). It was reported that down-regulation of caspase- 9 is a frequent event in patients with stage II colorectal cancer with poor clinical outcome (Shen et al., 2010). Studies by Devarajan et al. (2002) demonstrated that caspases-3 mRNA levels in samples from breast, ovarian, and cervical tumors were either found undetectable (breast and cervical tumor sample) or significantly reduced (ovarian tumor sample). Fong et al. (2006) observed a down regulation of both capase- 8 and caspase- 10 in a cDNA differential expression study and suggested that it may contribute to the pathogenesis of chorio-carcinoma.

\section{Deregulated Expression of Inhibitor of Apoptosis Proteins (IAPs)}

Dysregulated expression of Inhibitor of apoptosis proteins or IAPs has been observed in several cancers (LaCasse et al., 2008). Lopes et al. (2007) observed an irregular expression of the IAP family in pancreatic cancer cells and demonstrated that such expression pattern was also responsible for inducing resistance to cancer chemotherapy. The study concluded that substantial drug resistance correlated with the expression of cIAP-2 in pancreatic cells (Lopes et al., 2007). On the contrary, studies demonstrated that higher IAPs expression are associated with melanoma, lymphoma and gliomas (Ashhab et al., 2001) and was responsible for cisplatin and camptothecin resistance (Chen et al., 1999). Survivin, as potential IAP, is overexpressed in several cancers (Pennati et al., 2007). Interestingly, Small et al. (2010) observed that overexpressed survivin in hematopoietic cells were at an increased risk of hematological malignancies with less susceptibility to apoptosis in transgenic mice (Small et al., 2010). Survivin, together with XIAP is overexpressed in non-small cell lung carcinomas and these tumors were endowed with resistance against different apoptosis-inducing conditions (Krepela et al., 2009). A schematic of cellular pathways involved in apoptosis are shown in Figure 1.

\section{Virus and Cancer}

Over past 30 years, it has become remarkably apparent that several viruses play vital roles in the process of carcinogenesis. It is an estimated fact that $15-20 \%$ of all human malignancies are associated with viral infections (McLaughlin-Drubin and Munger, 2008). Oncogenic viruses can replicate inside the host cell without being detected by the host's immune surveillance system and by preventing apoptosis they can protect the cells from self-destruction (Ewald, 2010). Therefore, viruses can be essential experimental models to understand the regulation of major tumor suppressors, identification of major signaling cascades for genome maintenance, apoptotic response, and immune surveillance. Human tumor viruses either belong to RNA virus families including, Retroviridae, Flaviviridae or to DNA virus families such as-Hepadnaviridae, Herpesviridae, and Papillomaviridae. Major tumor viruses, which are linked with a wide range of human malignancies, are HTLV-1, HPV, HHV-8, EBV, HBV, and HCV. Some other viruses that play crucial roles in cancer progression are simian vacuolating virus $40, \mathrm{BK}$ virus, JC virus, human endogenous retroviruses, human mammary tumor virus, Torque teno virus (McLaughlin-Drubin and Munger, 2008). Marek's disease virus or MDV (also known as Gallid herpesvirus 2) is considered as an $\alpha$-herpesvirus, which causes oncogenic disease in domestic fowl (chickens) by producing $\mathrm{T}$ cell lymphosarcoma (lymphoma), visceral tumors and other clinical signs such as nerve lesions and immunosuppression (Rong et al., 2014). Gallid herpesvirus-2 (GaHV-2) genome integrates into the host genome by homologous recombination and induces transformation of latently infected cells, by modulating the expression of several viral and cellular genes (Gennart et al., 2015).

\section{Gammaherpesvirus and Cancers}

Members of the Herpesviridae family, Herpesviruses, are large, double-stranded DNA viruses with a genome size of 100$200 \mathrm{~kb}$, broad species tropism, and known to replicate in the nucleus of the host cell. These viruses are ubiquitous throughout the animal kingdom and are considered as the contributors to lymphomagenesis in immunodeficient humans. Based on their genomic organization, genome sequence and biological characteristics, herpesviruses are sub-classified as $\alpha$-, $\beta$-, and $\gamma$-herpesviruses. The $\gamma$-herpesviruses are lymphotropic and some of these viruses are capable of undergoing lytic 


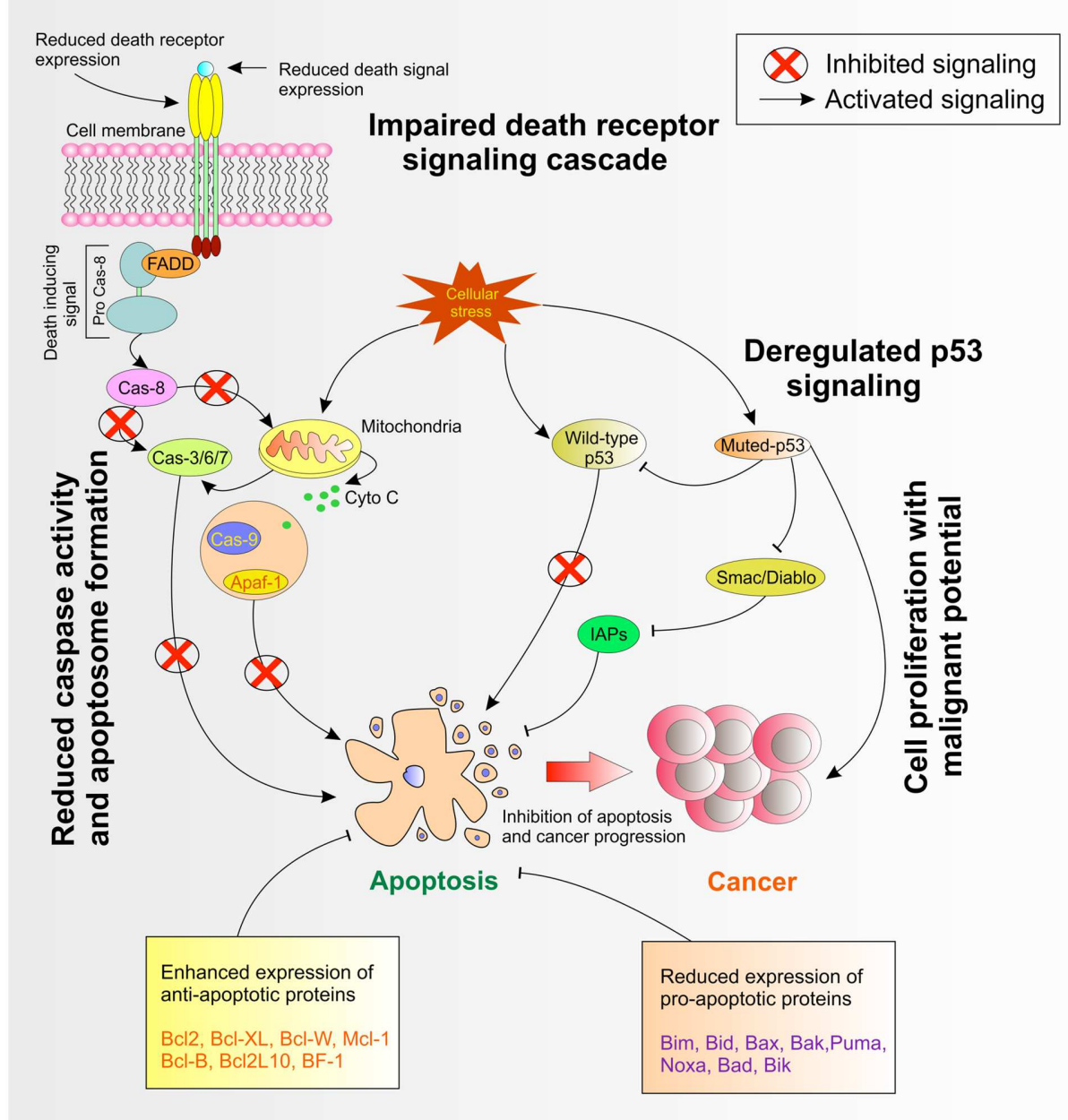

FIGURE 1 | Deregulated cellular pathways in apoptosis.

replication in epithelial cells (Klein, 1972). These tumor viruses establish a lifelong latency in the infected host. Interestingly, the $\gamma$-herpesviruses show similar genome organization as compared to the members of $\alpha$ - or $\beta$-subfamilies (Damania, 2004). The $\gamma$-herpesviruses are further divided into two genera: Lymphocryptoviruses (gamma-1 herpesviruses) and Rhadinoviruses (gamma-2 herpesviruses). Lymphocryptoviruses have been identified in higher primates and include EpsteinBarr virus (EBV) or Human herpesvirus 4 (HHV-4), whereas the rhadinoviruses are present in a wide range of mammalian species and these include Herpesvirus saimiri (HVS), Kaposi's sarcomaassociated herpesvirus (KSHV), or Human herpesvirus 8 (HHV8), Rhesus macaque rhadinovirus (RRV), Equine herpesvirus 2 (EHV-2), and Murine gammaherpesvirus 68 (MHV-68). Nearly, all the members of the $\gamma$-herpesvirus family share a common property, i.e., the ability to induce neoplasia in natural or experimental hosts (Figure 2). Among these $\gamma$-herpesviruses, $\mathrm{EBV}$ and KSHV are two oncogenic viruses that are linked to the development of multiple human malignancies in their natural hosts. EBV has been linked with several human malignancies, including, Burkitt's lymphoma, nasopharyngeal carcinoma (NPC), Hodgkin's disease and a subset of gastric cancers (Blacklow et al., 1971; Ablashi et al., 1985; Mueller, 1991; Magrath, 1992; Magrath et al., 1992; Damania et al., 2000a; Iizasa et al., 2012). Similarly, KSHV has been linked to Kaposi's sarcoma (KS), multicentric Castleman's disease (MCD), primary effusion lymphoma (PEL) and more recently, KSHVassociated Inflammatory Cytokine Syndrome (KICS; Chang et al., 1994; Cesarman et al., 1995; Soulier et al., 1995; Gessain et al., 1996; Uldrick et al., 2010; Polizzotto et al., 2012).

\section{Lymphocryptovirus}

Lymphocryptoviruses or LCVs are considered as gamma 1herpesviruses which are well known for infecting old-world primates (Dunkel et al., 1972). They exhibit a biphasic life cycle with a lifelong persistence and are capable of promoting malignancies (Cho et al., 1999). As a well-studied LCV, EpsteinBarr virus (EBV) was found only member known to cause infection in humans (Yajima et al., 2008). 


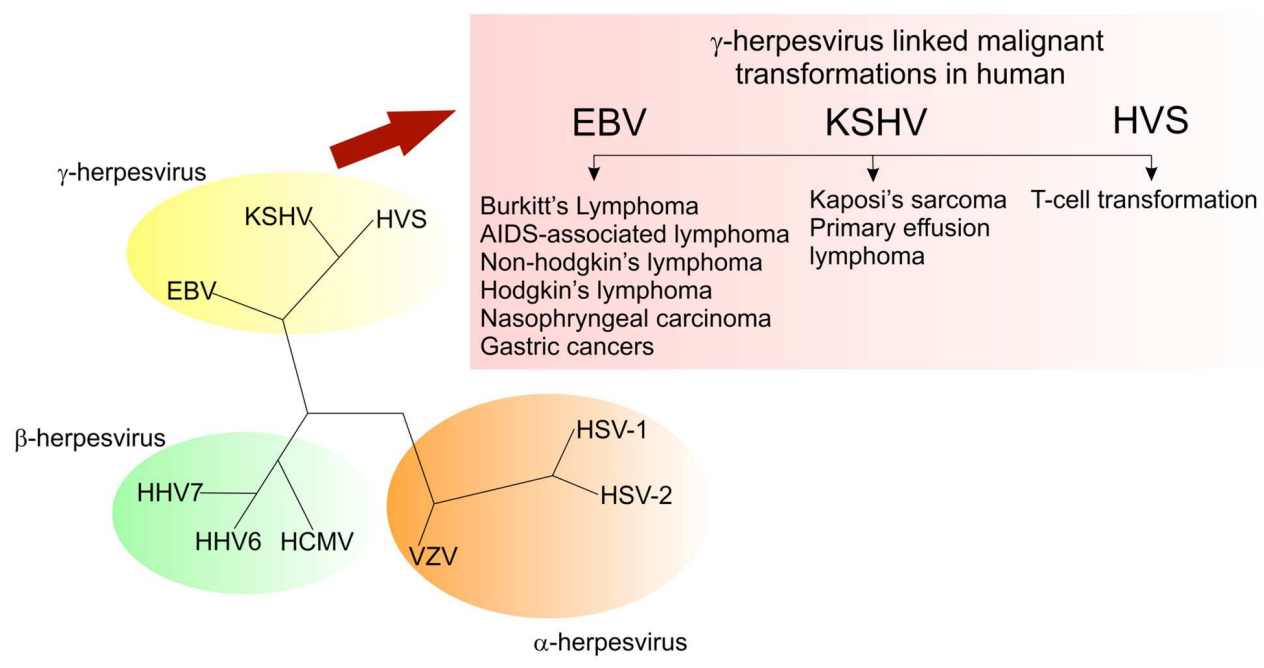

FIGURE 2 | Members of the gammaherpesvirus family have the ability to drive cell proliferation and tumorigenesis.

\section{Role of Epstein-Barr virus (EBV) antigens in cancer progression by modulation of apoptotic signaling}

EBNA1. Previous studies suggested that direct elimination of EBV from Burkitt's lymphoma (BL) cells induces apoptotic event (Kennedy et al., 2003). Although, most of the experimental evidences suggested that EBV infection mainly responsible for inhibiting apoptosis in cellular transformation but in some cases, EBV infection induces apoptotic response in human neutrophils and may represent an alternative mechanism by which EBV suppresses the immune response (Larochelle et al., 1998). Also, other report showed that EBV could inhibit cord blood monocytes derived dendritic cells (CBDC) phenotypic differentiation and induce CBDC apoptosis (Wang et al., 2012). EBV latent antigen EBNA1 has been anticipated to be involved in BL cell proliferation and resistance to apoptosis, therefore, conferring a selective benefit to malignant cells (FuentesGonzalez et al., 2013). Also, EBNA1 was found to have an anti-apoptotic effect in BL cells (Kutok and Wang, 2006). Several studies suggested that EBNA1 is sufficient to support the neoplastic growth of BL cells in vivo, independent of any other latent EBV antigens (Yamamoto et al., 2000). Moreover, studies by Kennedy et al. (2003) demonstrated that overexpression of EBNA1 mutants reduced cell survival and increased apoptosis in EBV-positive BL cells but not in EBV-negative B cells. Interestingly, their work suggested that EBNA1 is important for suppressing cell death in microenvironments (Kennedy et al., 2003). Recent report showed that expression of V-val subtype of EBNA1 in Human Embryonic Kidney cells promotes cell survival after serum withdrawal and provides the anti-apoptotic ability to those cells (Chao et al., 2014). In vivo EBNA1 has been confirmed to lower p53 levels (Cheng et al., 2009). Specifically, expression of EBNA1 but not a cellular ubiquitin-specific protease (USP7)binding mutant of EBNA1 was shown to reduce the accumulation of p53 and apoptosis in response to DNA damage in U2OS cells (Saridakis et al., 2005). Interestingly, transcriptional profiling of $\mathrm{Ad} / \mathrm{AH}$ carcinoma cells with and without stable EBNA1 expression showed that the presence of EBNA1 resulted in an increased expression of STAT1, a protein that contributes in multiple ways to apoptotic and non-apoptotic cell death (Wood et al., 2007). Other studies suggested that EBNA1 has multiple effects on the oxidative stress response that could affect apoptosis and DNA integrity (Frappier, 2012). Recently, Lu et al. (2010) observed that EBNA1 can contribute to the oncogenic process by up-regulating the apoptosis suppressor protein, survivin in EBV-associated B-lymphoma cells (Lu et al., 2010).

EBNA2. EBV nuclear antigen 2 (EBNA2) is the earliest latentcycle protein of EBV and is essential for B-cell immortalization, proliferation and survival as well as chemotaxis ( $\mathrm{Fu}$ et al., 2013). Studies by Pegman et al. (2006) demonstrated that in EBV-negative BL-derived cell lines EBNA2 up-regulates bfl-1 expression by interacting with EBNA2-CBF-1. These molecular interactions involve receptors of the classical Notch pathway. EBNA2 also up-regulates other anti-apoptotic proteins such as bfl-1, Bcl-xL, Bcl-2, and MCL-1 and induces the expression of pro-apoptotic proteins including, Bim and Bid (Kohlhof et al., 2009). Recent studies demonstrated that EBNA2 is crucial for suppressing Bik in EBV-negative B-cell lymphoma-derived cell lines and therefore, the host-virus interaction can prevent the pro-apoptotic consequence of transforming growth factor $\beta 1$ (TGF- $\beta 1$; Campion et al., 2014). Moreover, EBNA2 was found to inhibit the Sindbis virus (SV)-induced apoptotic response through the interaction with an orphan member of the nuclear hormone receptor superfamily, Nur77 (Lee et al., 2002).

EBNA3A. Genetic studies have revealed that both EBNA3A and EBNA3C are responsible for efficient immortalization in EBV infected B cells (Tomkinson et al., 1993). Studies by Cooper et al. (2003) indicated that EBNA3A overexpression impedes protection from c-myc-induced apoptosis in lymphoblastoid cells. Recombinant strategies to delete EBNA3 genes and the infection of EBV-negative BL cells with these viruses and challenging them with various cytotoxic drugs demonstrated 
that both EBNA3A and EBNA3C cooperate for both drug resistance and the down-regulation of the pro-apoptotic Bcl2 -family member Bim. The regulation of Bim was observed predominantly at the RNA level, with little evidence of posttranslational stabilization of Bim by EBV (Anderton et al., 2008). Several evidences strongly suggested that EBNA3A and EBNA3C together inhibit the initiation of BIM transcripts (Paschos et al., 2012). Previous study has also shown that heritable epigenetic modifications initiated by EBNA3A and EBNA3C in the $5^{\prime}$ regulator region of $\mathrm{BIM}$ play a vital role in determining the level of post-transcriptional BIM production expressed in EBVinfected B cells (Paschos et al., 2009).

EBNA3B. The co-activation activities of EBNA-3A and EBNA-3B are found to be around the half of EBNA3C (Lin et al., 2002). Although EBNA-3B is dispensable for B-cell transformation, both EBNA3A and EBNA-3C are essential (Chen et al., 2005). Among six latency-associated EBNAs, only EBNA3B is completely dispensable for B-cell transformation in vitro and could be a tumor suppressor (White et al., 2012). In contrast to EBNA$3 \mathrm{~A}$ and EBNA3C, both of which repress transcriptions of tumor suppressors, p14ARF, p16INK4A, and chemokine, CXCL10, EBNA-3B upregulates CXCL10 and has a growth inhibitory role (Kang and Kieff, 2015). Importantly, EBNA-3B-mutated B-cell lymphomas were frequently found and evident that EBNA$3 \mathrm{~B}$ inactivation drives lymphomagenesis and immune evasion (White et al., 2012).

EBNA3C. Functional p53 and its downstream effectors are deregulated by several viral antigens to protect host cells from p53-dependent apoptosis during cancer progression (Saha et al., 2010b) EBNA3C was observed to have potential inhibitory effects on p53-mediated activities (Yi et al., 2009). Several studies have shown that EBNA-3C can physically interact with p53 via the specific region, 130-190 amino acid residues in the $\mathrm{N}$-terminal domain which has also been shown to interact with several other important cellular factors, including SCFSkp2, pRb, c-Myc, cyclin A, cyclin E, cyclin D1, and RBP-Jк (Knight et al., 2004, 2005; Maruo et al., 2009; Saha et al., 2009, 2011). Studies have demonstrated that EBNA3C recruits MDM2 E3ubiquitin ligase activity for augmenting proteasome dependent degradation of p53 (Saha et al., 2009). Also, EBNA3C can form a p53-independent stable complex with both ING4 and ING5 in EBV-transformed LCLs (Saha et al., 2010a). Recently, it has been reported that EBNA3C strongly binds and stabilizes ATP-dependent RNA helicase DDX20 or Gemin3 expression in EBV-transformed cells (Cai et al., 2011). As a result of EBNA3C-Gemin3 interaction, Gemin3 was found to form a complex with p53 and this is crucial for inhibiting p53dependent transcriptional activity and apoptosis (Cai et al., 2011). Interestingly, EBNA3C expression was observed to abrogate p73mediated apoptotic response in p53-null cells (Sahu et al., 2013). Recent studies by Saha et al. (2012) demonstrated that EBNA$3 \mathrm{C}$ could directly regulate E2F1 functions to modulate both, cell cycle and apoptotic activities in EBV-transformed B-lymphoma cells. Moreover, EBNA3C was found to interact and differentially regulate the functions of Interferon regulatory factors 4 and 8 in lymphoblastoid cells (LCLs) for apoptotic inhibition (Banerjee et al., 2013). In addition, EBNA3C regulates apoptosis by altering the signaling of several cellular kinases including, Pim-1, Aurora kinase-B (AK-B; Jha et al., 2013a; Banerjee et al., 2014).

EBNA-LP. EBNA-LP is considered as a critical regulator of EBV-induced B-cell immortalization, based on the studies that demonstrated less efficiency in the phenotype for recombinant EBNA-LP mutant viruses (Mannick et al., 1991). EBNA-LP has also been observed to interact with several cellular proteins, including oncogenes and tumor suppressors (pRb, p53, p14ARF, and Fte1/S3a), heat shock proteins (hsp70 and hsp72/hsc73), cell-cycle regulatory molecules (DNA-PKcs and HA95) and antiapoptotic (HAX-1) protein (Szekely et al., 1993; Mannick et al., 1995; Kawaguchi et al., 2000; Dufva et al., 2001; Han et al., 2001; Kashuba et al., 2005). Several studies suggested that truncated form of the EBNA-LP protects some BL cells against caspasedependent apoptosis by impeding the functions of protein phosphatase 2A (Garibal et al., 2007). In a study by Kawaguchi et al. (2000) using the yeast two-hybrid system, EBNA-LP was found to interact with HAX-1 and it is plausible that EBNALP affects the activities of HAX-1 in the regulation of apoptosis during the EBV-induced immortalization process.

LMP1. LMP1 not only up-regulates anti-apoptotic proteins to provide support for viral replication but also potentiates apoptosis (Zhang and Huang, 2009). LMP1 stimulates proapoptotic gene PAC1 as well as anti-apoptotic genes such as Bcl-2A1/Bfl-1 and A20 (Dirmeier et al., 2005). LMP1 mediated induction of pro-apoptotic genes are likely to be involved in lymphocyte proliferation (Tibbetts et al., 2003). Studies have suggested that the immortalization effect of LMP-1 on B-lymphomas is mediated by the Bcl-2 through a possible cooperation between Bcl-2 and MCL-1. Lu et al. (1997) suggested that LMP-1-induced apoptosis is specifically blocked by the abnormal expression of Bcl-2 or co-expression of LMP-1 and Bcl2 in epithelial cells (RHEK-1 cells). Down-regulation of Bcl-2 was observed by direct silencing of LMP-1 in an EBV-transformed B-cell line (Noguchi et al., 2001). Several studies also suggested the role for LMP-1 to induce the expression of Bcl-2 in BL cell lines in vitro (Finke et al., 1992). Moreover, a positive link between LMP-1 and Bcl-2 has been observed in acquired immune deficiency syndrome (AIDS)-related primary brain lymphomas in vivo as well as in NPC (Camilleri-Broet et al., 1995). Other studies were strongly supported by the findings that the expression of bfl-1 suppresses apoptosis stimulated by the aminoterminal six-transmembrane domain (6TM) of LMP-1 (Pratt et al., 2012). Studies by Kim J.H. et al. (2012) also demonstrated that up-regulation of MCL-1 by LMP-1 promotes survival of rituximab-treated B-cell lymphoma cells. Interestingly, the down-regulation of MCL-1 expression is inhibited by LMP-1 in response to apoptotic stimulation (Fu et al., 2013). Interestingly, overexpression of wild type LMP1 was found to be associated with a significant increase in CD95-mediated apoptosis (Le Clorennec et al., 2006). Moreover, several studies suggested that the ability of LMP1 to activate NF-кB was responsible for inducing A20 zinc finger protein to give protection from the cytotoxic effects of TNF- $\alpha$ (Young et al., 1997). Studies by Lu et al. (1996) indicated that higher level of LMP1 expression was 
responsible for inducing growth arrest and apoptosis for rodent cell transformation.

LMP2A. EBV latent membrane protein 2A (LMP2A) was identified in germinal center B cells (Babcock et al., 2000), but its transcripts were detected in all forms of EBV latency, including, resting memory $\mathrm{B}$ cells, infectious mononucleosis, Hodgkin lymphoma, BL, and post-transplant lymphoproliferative disorder (PTLD; Thorley-Lawson and Gross, 2004). Therefore, LMP2A was considered crucial in EBV-associated diseases and studies have demonstrated that it has a critical function to rescue cells from apoptosis by potentially altering the balance of proapoptotic and pro-survival $\mathrm{Bcl} 2$ family members, particularly by mediating the expression of $\mathrm{Bcl}-\mathrm{xL}$ and $\mathrm{Bcl}-2$ (SwansonMungerson et al., 2010). Importantly, both the PI3K/Akt and the Raf/ERK MEK/ERK signaling increases NF- $\kappa \mathrm{B}$, which is a critical mediator of Bcl-xL (Steelman et al., 2004). It has been reported that LMP2A possibly sustains cell survival by modifying $\mathrm{Bcl}-\mathrm{xL}$ and Bcl-2 expression levels in absence of B-cell receptor signaling (Portis and Longnecker, 2004). Other studies also have demonstrated that LMP2A can bypass the entire $\mathrm{p} 53$ pathway in lymphomagenesis involving c-MYC (Bieging et al., 2009).

EBERs. The two EBV-encoded small RNAs (EBERs) were identified as EBER-1 and EBER-2. They are small nuclear RNAs transcribed by RNA polymerase III and are the most abundantly expressing EBV transcripts (Rymo, 1979). Several studies have shown that EBV-mediated inhibition of apoptosis and up-regulation of the $\mathrm{Bcl}-2$ protein are essential for the malignant phenotype (Marin et al., 1995). Moreover, previous reports also provided direct evidence that EBV induces $\mathrm{Bcl}-2$ expression by blocking the activation of the double-stranded RNA-dependent protein kinase (PKR; Komano et al., 1999). Interestingly, studies by Wong et al. (2005) suggested that EBER-induced up-regulation of Bcl-2 expression leads to an inactivation of PKR and inhibition of p38 MAPK and C-jun phosphorylation. Additionally, EBER expression may confer an apoptotic-resistant phenotype in immortalized nasopharyngeal epithelial cells (Wong et al., 2005).

BARTs. EBV was the first human virus in which the expression of miRNAs, such as MIR-BamHI A rightward transcripts 5 (BART5) was identified (Pfeffer et al., 2004). Unlike cellular miRNAs (Grundhoff et al., 2006), the roles of most EBV miRNAs are well documented. Previous studies suggested that EBV miRNAs are central mediators of viral gene expressions (Yin et al., 2008), however, recent studies demonstrated that MIR-BART5 promotes host cell survival by targeting PUMA expression and contributes to the establishment of latent infection in NPC and germinal center B-cells (Choy et al., 2008). MIR-BARTs may be important in epithelial cells carcinogenesis as they are abundantly expressed in latently infected epithelial cells as compared to the B-cells (Cai et al., 2006). Recent study also suggested the role of EBV-BART microRNAs in targeting the pro-apoptotic protein, Bim (Marquitz et al., 2011). Most of the viral miRNAs belong to the herpesviruses, including human $\alpha$-herpesviruses such as herpes simplex virus 1 (HSV-1) and HSV2 , avian $\alpha$-herpesviruses MDV1 (Marek's disease virus type 1) and MDV2 (Marek's disease virus type 2), $\beta$-herpesvirus human cytomegalovirus (HCMV), and $\gamma$-herpesviruses EBV and KSHV (Gottwein and Cullen, 2008). Interestingly, recent studies by $\mathrm{Xu}$ et al. (2011) demonstrated that MDV1 microRNA miR-M3 suppresses cisplatin-induced apoptosis by targeting SMAD2 of the TGF- $\beta$ Signal Pathway.

\section{Rhadinoviruses}

\section{Kaposi's sarcoma-associated herpesvirus (KSHV)}

KSHV was discovered in 1994 from the AIDS-associated KS (Kaposi's sarcoma) lesions (Chang et al., 1994). KSHV is detected in all cases of KS that develop in HIV-infected as well as HIV-negative individuals. In addition, KSHV sequences are rapidly identified in two other lymphoproliferative and neoplastic disorders: B-cell lymphoma called primary effusion lymphoma (PEL), and the a plasmablastic variant of Multicentric Castleman's disease (MCD), which contains large plasmablastic cells characterized by the expanded germinal centers with B-cell proliferation and vascularization. KSHV is also associated with several acute inflammatory syndromes (Ganem, 2006). There is also a report of KSHV-linked germinotropic lymphoproliferative disorder in HIV-seronegative individual (Du et al., 2002)

\section{Role of KSHV antigens in modulating apoptotic signaling for cancer progression}

LANA. KSHV LANA (Latency-associated nuclear antigen) encoded by ORF73 is KSHV's major latency protein and is constitutively active in $\mathrm{KS}, \mathrm{MCD}$, and PEL cells. The multifunctional nuclear phosphoprotein, LANA is crucial for KSHV genome maintenance and segregation and plays a key role in regulating several cellular pathways critical for oncogenesis. In addition to being guardian of KSHV latency, LANA binds to and inhibits the cell cycle checkpoint protein and tumor suppressor, p53 as well as transforms primary rat embryo fibroblast (Friborg et al., 1999; Radkov et al., 2000; Borah et al., 2004; Si and Robertson, 2006; Liu et al., 2007). Moreover, LANA interacts with G1-S checkpoint proteins, pRB and GSK-3 (glycogen synthase kinase 3), a negative regulator of $\beta$-catenin and modulates G1-S transition (Fujimuro et al., 2003). LANA prolongs the life span of primary human umbilical vein endothelial cells in culture and makes them less susceptible to apoptosis (Watanabe et al., 2003). Like many other cellular proteins, LANA binds to the phosphorylated DNA-damage response protein, $\gamma \mathrm{H} 2 \mathrm{AX}$ and the cellular replication fork factors, Timeless and Tipin for LANA-mediated KSHV episome persistence (Dheekollu and Lieberman, 2011; Dheekollu et al., 2013; Jha et al., 2013b). It also associates with different host cellular proteins involved in transcriptional regulation, such as CBP, RING3, activating transcription factor-4/cyclic AMP response element binding protein-2 and mSin3A (Platt et al., 1999; Krithivas et al., 2000; Lim et al., 2001; Verma et al., 2007). These associations have anti-apoptotic and anti-proliferative effects in various KSHVinfected cell lines. A recent study showed that LANA promotes the induction of chromosomal instability through its interaction with Bub1, one of the important spindle checkpoint proteins (Sun et al., 2014). Additionally, LANA was found to dysregulate Bub1 activity leading to aberrant chromosome replication, thus 
promoting oncogenesis (Sun et al., 2014). A 2014 study by Lu et al. (2014) demonstrated LANA through the interaction with AK-B, can induce phosphorylation of survivin at T34 residue to promote KSHV latent DNA replication and prevent apoptosis. LANA also helps in evading the host's immune surveillance system and allows the virus to persist indefinitely in the infected host (reviewed in Zaldumbide et al., 2007; Kwun et al., 2011; Uppal et al., 2014). LANA specifically blocks CIITA expression by suppressing the IRF-4-mediated transcription to disrupt the expression of MHC II (Cai et al., 2013). Additionally, LANA down-regulates MHC II expression by disrupting enhanceosome assembly through its binding with the RFX (Regulatory Factor X) Complex (Thakker et al., 2015).

$v$-Cyclin. KSHV ORF72 encoded $v$-Cyclin, expressed during viral latency, is the viral homolog of cellular D-type cyclins (Li et al., 1997). It contributes to the abnormal characteristics of KS spindle cells and proliferation in PEL cells. Interestingly, expression of the KSHV $v$-Cyclin induces cellular apoptosis and B-cell lymphomas in p53-deficient transgenic mice (Verschuren et al., 2002). KSHV $v$-Cyclin is expressed along with KSHV vFLIP from a bicistronic mRNA and silencing of either of these KSHV latent protein by shRNA/siRNA has been shown to induce apoptosis in PEL cells (Guasparri et al., 2004). v-Cyclin shares sequence and functional homology with cellular cyclin D2 and can bind and activate the cyclin-dependent kinases, namely CDK6, CDK4, and CDK2 (Godden-Kent et al., 1997; Radkov et al., 2000; Hume and Kalejta, 2009; Pekkonen et al., 2014). When in complex with CDKs, $v$-Cyclin is able to phosphorylate and inactivate many substrates linked to CDKs, including, tumor suppressor protein pRb, cdk inhibitor p27 (Kip) and the anti-apoptotic protein Bcl-2, thereby deregulating normal cell cycle progression (Godden-Kent et al., 1997; Ellis et al., 1999; Ojala et al., 2000). The $v$-cyclin/CDKs complexes are insensitive to CDK inhibitors such as p16INK4a, p21CIP1, and p27KIP1, and can stimulate the cell cycle progression into S-phase (Jarviluoma et al., 2004). In contrast, the expression of $v$-Cyclin in cells with elevated levels of CDK6 triggers cell death independent of p53 and pRb, after the cells enter into S-phase (Ojala et al., 1999). These evidences indicate that $v$-Cyclin is likely to have both growth stimulating and apoptotic functions in KS tumorigenesis.

$v$ FLIP. KSHV ORF K13 encoded and latency-associated $v$ FLIP or FADD-like interleukin-1-beta-converting enzyme (FLICE or caspase-8)-inhibitory proteins, is a viral homolog of cellular FLIP (Thome et al., 1997). This viral protein from KSHV is structurally related to death effector domain (DED) and can bind to the adaptor proteins (TRADD and FADD) of the Fas/TNFR signaling pathway via their two tandem DEDs to inhibit CD95death receptor-induced apoptosis (Thome et al., 1997). Several studies suggested that $v$ FLIP induces anti-apoptotic transcription factor NF- $\mathrm{B}$ via binding to IKK $\alpha$, IKK $\beta$, RIP, and the NEMO complex (Liu et al., 2002; Matta et al., 2003). In support of this finding, another study showed that KSHV $v$ FLIP induction of NF- $\kappa$ B activity impairs autophagosome elongation in latently infected cells (Lee et al., 2009). This showed that the expression of cellular and viral FLIP (cFLIP and KSHV $v$ FLIP) suppresses starvation or rapamycin-induced autophagic cell death of KSHV infected B-lymphocytes, by preventing E3-like enzyme, ATG3 from binding and processing LC3. These reports confirm that KSHV $v$ FLIP serves as both, an anti-apoptotic as well as an anti-autophagic viral protein, which is essential for the survival and transformation of infected cells (Lee et al., 2009). KSHV $v$ FLIP oncoprotein also induces B-cell trans-differentiation and potentially contributes to immune dysfunction during tumor development in mice (Ballon et al., 2011).

Kaposin. KSHV ORF K12 encoded Kaposin, is a latent oncogenic protein with potential to transform cells in nude mice and in a fibroblast-transformation assay (Muralidhar et al., 1998; Kliche et al., 2001). There are three isoforms of Kaposin, named as A, B, and C (Sadler et al., 1999). An earlier study showed that Kaposin A, the smallest isoform, directly interacts with cytohesin1, a guanine nucleotide exchange factor for ARF GTPases, to regulate integrin-mediated cellular transformation and activation of the ERK/MAPK pathway (Kliche et al., 2001). Kaposin B enhances the stabilization of PROX1 mRNA, the master regulator of lymphatic endothelial cell differentiation, during lymphatic reprogramming of vascular endothelial cells by KSHV (Yoo et al., 2010).

$v B c l$-2. KSHV ORF16 encodes protein $v \mathrm{Bcl}-2$ with homology to cellular anti-apoptotic protein, Bcl-2, which is characterized by its ability to modulate cell death by dimerizing with other Bcl2 family members, such as Bax and Bak (Cheng et al., 1997). The $v \mathrm{Bcl}-2$ protein is expressed as an early gene during lytic replication and has been shown to inhibit apoptosis to promote viral life cycle through the inhibition of pro-apoptotic $\mathrm{BH} 3$ domain-containing proteins (Sun et al., 1999; Flanagan and Letai, 2008). In addition to apoptosis, several studies indicate that vBcl2 contributes to immune evasion in all gammaherpesviruses via inhibition of autophagy (Polster et al., 2004). Contrary to the cellular counterpart, vBcl-2-mediated inhibition of autophagy involves direct and robust interaction of vBcl-2 protein with host Beclin I, the main target of $\mathrm{vBcl}-2$ proteins of $\mathrm{KSHV}$ during chronic infection (Liang et al., 2015). Interestingly, Beclin I-mediated inhibition of autophagy and suppression of apoptosis by vBcl-2 are considered as important mechanisms that might contribute to persistent latent infection and the oncogenic potential of KSHV.

$v I R F s$. KSHV encodes four $v$ IRFs, namely, $v$ IRF-1, $v$ IRF-2, $v$ IRF3 , and $v$ IRF-4, that are homologs of the cellular IRF proteins [interferon (IFN)-regulatory factors], a large family of cellular transcription factors that drive the expression of type I IFNs (IFN $\alpha$ and $\beta$ ), which are produced in nearly all cell types to trigger cell's innate responses to virus infection by establishing the "anti-viral state" (reviewed in Jacobs and Damania, 2011). They are also known to play a key role in the modulation of cell growth, differentiation and cell death. All KSHV-vIRFs have been independently identified to subvert cell cycle arrest by inhibiting p53-mediated apoptosis, either by targeting p53 itself or by targeting its modulators, such as MDM2, HAUSP, and ATM, a function that could potentiate $v$ IRF-mediated oncogenesis (Baresova et al., 2013). Of the four KSHV $v$ IRFs, only $v$ IRF$1, v$ IRF-2, and $v$ IRF-3, are shown to effectively inhibit both 
IFN production and signaling in the infected cells (Baresova et al., 2013). Importantly, both $v$ IRF-1 and $v$ IRF-3 inhibit p53-induced apoptosis by interacting with the central DNAbinding domain (DBD) of p53 and ATM kinases, and greatly reduce the levels of p53 phosphorylation on serine residues S15 (Shin et al., 2006; Baresova et al., 2014). This results in an increased p53 ubiquitination by MDM2 that predisposes p53 toward proteasome-mediated degradation. Also, $v$ IRF-1 inhibits the transforming growth factor-beta (TGF- $\beta$ ) signaling through its targeting of Smad 3 and Smad 4 proteins (Seo et al., 2005). The $v$ IRF-3 has been identified as an oncogene required for proliferation and survival of KSHV-infected cultured PEL cells (Wies et al., 2008). The silencing of $v$ IRF-3 expression by various RNAi approaches resulted in reduced proliferation and increased activity of caspase- 3 and/or caspase-7. In a recent study, $v$ IRF- 4 but none of the other $v$ IRFs, was shown to interact with CSL/CBF1 signaling, the major downstream effector of the Notch signal transduction pathway (Baresova et al., 2013). Moreover, $v$ IRF-1 and $v$ IRF-2 act as modulators of the immune system by repressing activation-induced cell death (AICD) via modulation of TCR/CD3-mediated induction of CD95L (Chow et al., 2000). Additionally, vIRF1 has similar DNA-binding domains to IRF-1 and interacts with p300/CREB-binding protein (CBP) transcription complex, that is required for IRF1- and IRF3mediated transcription of type I IFNs (Burysek et al., 1999a). The $v$ IRF-2 is shown to interact with cellular IRF-1, 2, and 8 as well as NFkB RelA and p300 (Burysek et al., 1999b). The $v$ IRF-3 interacts with cellular IRF-5 and inhibits IRF-5-mediated activation of IFN promoter (Wies et al., 2009). Recently, vIRFs 1 and 2, but not $v$ IRF3, have been reported to suppress endogenous IFN $\beta$ message and protein expression following TLR3 activation (Jacobs et al., 2013).

$v M I P$. KSHV ORK K6, ORF K4, and ORF K4.1 encodes for three chemokines or macrophage-inhibitory proteins ( $v$ MIPs or $v$ CCLs), homologous to cellular chemokines/MIPs: viral CC-chemokine ligand-1 ( $v$ CCL-1 or $v \mathrm{MIP}-1)$, ligand-2 ( $v \mathrm{CCL}-$ $2 / v \mathrm{MIP}-2$ ) and ligand-3 ( $v$ CCL-3/vMIP-3), respectively (Nicholas et al., 1997). In fact, $v$ MIP-1 and $v$ MIP-2 are more homologous to one another than with cellular MIPs, indicating a gene duplication event during the virus evolution (Moore et al., 1996). Interestingly, vMIP-1 is a ligand and agonist of host CCchemokine receptor (CCR8; Endres et al., 1999), whereas vMIP-3 is shown to be specific agonist for host CCR4 (Stine et al., 2000). In addition, $v$ MIP-3, when expressed in KS lesions, stimulates angiogenesis, and selectively chemo attracts TH2-type T cells, indicating an important role of $v$ MIP-3 in the pathobiology of KS (Stine et al., 2000). The receptors targeted by $v$ MIP- 2 indicate evasion from a cytotoxic immune response via Th2 polarization and blocking of leukocyte trafficking.

K1. KSHV K1 is a transmembrane glycoprotein encoded by the first ORF of the KSHV genome. Initial characterization of K1 protein indicated an early lytic gene expression pattern and identified a highly conserved and functional immunoreceptor tyrosine-based activation motif (ITAM) on the short cytoplasmic tail at its C terminus (Lee et al., 1998a, 2003; Lagunoff et al., 1999). In B lymphocytes, the phosphorylation of ITAMs by protein tyrosine kinases is shown to activate various cellular signal transduction proteins carrying Src homology 2 (SH2) domains, such as PI-3K (p85)/Akt/mTOR, PLC $\gamma_{2}$, Syk, Cbl, Vav, Lyn, RasGAP (Tomlinson and Damania, 2004; Lee et al., 2005; Prakash et al., 2005), and to induce NFאB, nuclear factor of activated T cells (NFAT), Oct-2 and AP-1 (Prakash et al., 2005). Consequently, K1 expression inhibits proapoptotic proteins and increases the longevity of KSHV-infected cells. The activation of these ITAM-based signal transduction events also contributes to the oncogenic potential of $\mathrm{K} 1$ as suggested by tumor formation in mice by K1-transformed rodent fibroblasts and K1-transgenic mice (Lee et al., 1998b). In addition, K1 activation of Akt leads to inactivation of proapoptotic forkhead (FKHR) transcription factor family that protects cells from FKHR- and Fas-mediated apoptosis (Tomlinson and Damania, 2004). KSHV K1 protein is reported to immortalize and extend the life span of endothelial cells in culture (Wang et al., 2006). The expression of K1 in endothelial cells results in the up-regulation of secreted VEGF and MMP-9. In a recent study, Wen and Damania (2010) identified Hsp90 and ER-associated Hsp40/Erdj3 as cellular binding partners of $\mathrm{K} 1$, essential for its anti-apoptotic potential.

K15. The gene encoding KSHV K15, a putative integral transmembrane protein, is positioned at the 3' end of the KSHV genome (Choi et al., 2000). Two highly divergent forms of K15 have been identified: the predominant $(\mathrm{P})$ and minor $(\mathrm{M})$ forms (Poole et al., 1999). K15 is weakly expressed in latently infected PEL cells, but is robustly induced on lytic reactivation with chemical inducers such as phorbol esters (Choi et al., 2000). K15 isolates have a complex splicing pattern and yield multiple K15 proteins containing 4-12 transmembrane spanning domains and a short cytoplasmic domain (Glenn et al., 1999). The short cytoplasmic domain of K15 contains potential SH2- and SH3binding motifs, a YASIL sequence (necessary for the activation of NF- $\kappa$ B and Ras/MAPK signaling pathways) and binding sites for Src family cellular tyrosine kinases and TRAFs 1, 2, and 3 (Glenn et al., 1999; Brinkmann et al., 2007). K15 is capable of initiating several cellular signal transduction pathways, such as Ras/MAPK, JNK/SAPK, and NF-кB (Brinkmann et al., 2003, 2007; Cho et al., 2008) as well as the NFAT/AP1 transcription factors (Cho et al., 2008). K15 also induces the expression of multiple cellular cytokines and chemokines including IL6, IL8, CCL20, CCL2, CXCL3, IL- $1 \alpha / \beta$, and Cox2 (Brinkmann et al., 2007; Wang et al., 2007). Studies by Sharp et al. (2002) identified cellular HAX1 (HS associated protein X-1), an anti-apoptotic protein shown to inhibit Bax-induced apoptosis, as a binding partner to the $\mathrm{C}$ terminus of $\mathrm{K} 15$, both in vivo and in vitro, inferring $\mathrm{K} 15$ may play a role in maintaining latency and/or preventing apoptosis (Wong and Damania, 2006). Like EBV LMP2A, the expression of K15 and $\mathrm{K} 1$ led to the survival of BCR-negative human B cells prone to apoptosis (Steinbruck et al., 2015).

RTA. KSHV RTA (Replication and Transcription Activator), encoded by ORF50, functions as the master regulator of the transition from latent-to-lytic replication (Sun et al., 1998, 1999). RTA plays a pivotal role as both an initiator and regulator of KSHV lytic DNA replication as the genetic mutation of RTA leads to impaired lytic reactivation and DNA replication 
(Sun et al., 1998; Xu et al., 2005). KSHV RTA autoactivates its own promoter and transactivates other important lytic genes, namely vIL-6 (Deng et al., 2002; Bu et al., 2008), polyadenylated nuclear RNA (PAN RNA, reviewed in Rossetto and Pari, 2014), ORF57 (MTA; Lukac et al., 2001; Byun et al., 2002), K-bZIP (Lukac et al., 2001), vIRF1 (ORF-K9; Ueda et al., 2002), ORF-K1 (Bowser et al., 2006), small viral capsid protein (ORF65), ORF56, SOX (ORF37), vOX, and ORF52, by binding to the lytic gene promoters containing RTA-response element (Ueda et al., 2002; Song et al., 2003; Fritz et al., 2006). KSHV LANA is also known to repress lytic reactivation and RTA-mediated autoactivation (Lan et al., 2004, 2005). Studies by Nishimura et al. (2003) found that KSHV RTA induced caspase activation and cell death by apoptosis in uninfected cells but not in infected cells. These results suggested that RTA is an apoptosis inducer that is blocked by an antiapoptotic pathway in KSHV-infected cells (Nishimura et al., 2003). A study by Gao et al. (2011) reported that the upregulation of the cellular anti-apoptotic $\mathrm{Bcl}-2$ protein by RTA through its binding with $\mathrm{CCN}_{9}$ GG-like RTA resonsive elements (RREs)/motifs promotes lytic reactivation and enhanced virion production. These results indicate the existence of a distinct, apoptosis-triggered, accelerated RTA-independent replication pathway with clinical significance for the treatment of KSHVassociated neoplasms (Gao et al., 2011). Interestingly, RTA encodes an ubiquitin E3 ligase activity that targets multiple cellular and viral proteins, such as IRF-7, a critical mediator of type I IFN induction, for proteasome-mediated degradation (Yang et al., 2008). Since, IFN signaling plays a critical role in suppressing viral lytic replication, this finding suggests that RTA may follow an unexpected regulatory strategy for overcoming the host innate immune defenses during KSHV reactivation. Another study reported RTA-mediated degradation of the Heyl repressor protein through the Ubiquitin Proteasome pathway (Gould et al., 2009). Heyl degradation disrupts the interaction between Heyl and the co-repressor mSin3A. Heyl suppresses RTA expression by direct binding to the RTA promoter. RTA is known to up-regulate its own expression by targeting Heyl protein for degradation. Taken together, these results strongly suggest that RTA regulates viral lytic replication by promoting protein degradation of several cellular repressors. Additionally, recent studies have identified that RTA displays a SUMOtargeting ubiquitin ligase (STUbL) type activity, and is capable of ubiquitylation of SUMO and SUMO conjugates in vitro and in vivo. Thus, RTA is an ubiquitin ligase that targets SUMO-containing proteins, such as sumoylated K-bZIP and promyelocytic leukemia (PML) nuclear bodies (Izumiya et al., 2013).

K-bZIP. KSHV K-bZIP, also known as lytic replicationassociated protein (RAP) is a basic leucine zipper-containing protein that is encoded by KSHV K8 (Lin et al., 1999). KSHV $\mathrm{K}-\mathrm{bZIP}$ is dispensable for lytic reactivation, however, it is crucial for virus production in KSHV-infected cells (Kato-Noah et al., 2007; Rossetto et al., 2007; Lefort and Flamand, 2009; Wang et al., 2011). K-bZIP physically interacts with and represses RTA-mediated transactivation of viral promoters and RTA autoactivation through its basic domain (aa122-189) and a specific RTA region (aa499-550; Izumiya et al., 2003). K-bZIP has been shown to bind and up-regulate the cellular transcription factor CCAAT/enhancer-binding protein- $\alpha(\mathrm{C} / \mathrm{EBP} \alpha)$ and p21C1P-1 protein, resulting in G0/G1 cell cycle arrest in lytically induced cells (Wang et al., 2003). K-bZIP also efficiently binds to the PRDIII-I region of the IFN- $\beta$ promoter and prevents the attachment of activated IRF- 3 to the IFN- $\beta$ promoter sequence, suggestive of antagonizing effects exerted by $\mathrm{KSHV}$ on type I IFN pathways (Lefort et al., 2007, 2010). Most interestingly, a recent study identified K-bZIP as a SUMO E3 ligase or SUMO adaptor with specificity towards SUMO-2/3 (Chang et al., 2010). In addition, K-bZIP-mediated SUMO-2/3 specific modification on the KSHV genome post reactivation, are found to negatively regulate lytic gene expression and viral reactivation (Chang et al., 2013).

\section{Herpesvirus saimiri (HVS)}

Herpesvirus saimiri is an oncogenic gammaherpesvirus that establishes persistent and replicative infections in different species of primates and transforms human $\mathrm{T}$ cells (reviewed in Fickenscher and Fleckenstein, 2001). HVS causes a nonpathogenic, latent infection in its natural hosts, the squirrel monkey, however, in the New World primates such as the common marmosets, it results in severe and rapidly progressing T-cell lymphomas. Furthermore, HVS leads to a lifelong persistent infection primarily in T-lymphocytes. Like other members of the rhadinovirus family, HVS has pirated a number of cellular genes to regulate cell cycle, evade immune surveillance and to inhibit apoptosis.

\section{Role of HVS antigens in cancer progression by modulation of apoptotic signaling}

Tip (tyrosine kinase-interacting protein) encoded by HVS subtype C, located downstream of Stp gene, is a transforming protein important for viral transformation. HVS Tip has been reported to induce and immortalize infected human T-cells in vitro (Biesinger et al., 1992). Tip has multiple binding sites for cellular proteins. Indeed, Jae Jung's group has reported that the HVS Tip interaction with p80 and subsequent recruitment of Lck and TCR/CD3 complexes to lipid rafts markedly inhibits the T-cell receptor (TCR)-mediated intracellular signal transduction and CD4 surface expression. Strikingly, these two interactions are reported to be functionally and genetically separable, i.e., the interaction of its $\mathrm{N}$-terminal region with p80 is responsible for TCR down-regulation, whereas, the interaction of its C-terminal domain with Lck governs the CD4 down-regulation (Park et al., 2002, 2003; Cho et al., 2004, 2006). In addition, HVS Tip protein binding to Lck kinase requires $\mathrm{SH} 3$ Binding motif (SH3B) and C-terminal Src-related Kinase Homology (CSKH) element of Tip (Jung et al., 1995). Recently, the group also reported that the association of membrane-proximal amphipathic helix with Tip's transmembrane (TM) domain is sufficient for localization to lipid rafts and deformation of cellular membrane, which in turn directs Tip's lysosomal trafficking and selective TCR down-regulation (Min et al., 2008). Interactions between the phosphorylated peptides of HVS Tip and the Src homology 
2 (SH2) domains of STAT3 and STAT6 facilitate Src kinasemediated STAT-activation and T-cell proliferation (Mazumder et al., 2012). Another group recently reported that the N-terminal end sequence of Tip associates with and inhibits cellular retromer activity, thus leading to CD4 down-regulation and efficient T-cell transformation in an IL-2 independent fashion (Kingston et al., 2011). Tip can also induce T-cell transformation independent of IL-2 by constitutively activating the STAT6 transcription factor by interacting with and phosphorylating STAT6 (Kim Y. et al., 2012). Tip has been found to activate the serum response element (SRE) in a Lck and Src-family kinase interaction-dependent fashion, indicating its potential role in actin-regulated transcription and transformation of human T cells (Katsch et al., 2012).

Herpesvirus saimiri encodes a potent complement inhibitor, a structural homolog of complement control proteins, $\mathrm{CCPH}$ that inhibits $\mathrm{C} 4 \mathrm{~b}$ as well as $\mathrm{C} 3 \mathrm{~b}$ deposition on the target cells, exposed to complement, thus allowing HVS to evade the host complement attack (Singh et al., 2006; Reza et al., 2013). HVS CCPH effectively inactivates complement by supporting factor I-mediated inactivation of complement proteins, C3b and C4b. In a recent study, Reza et al. (2013) performed substitution mutagenesis of $\mathrm{CCPH}$ residues (sCCPH mutants) and demonstrated that ionic charges within amino acids form a major component of binding interface between $\mathrm{CCPH}$ and its interacting partners. These charges are reported to be crucial for $\mathrm{CCPH}$ 's interaction in human and viral complement regulators. In addition, the HVS genome encodes for one or more viral cytokines to promote survival of the infected cell and escape from the host immune responses. HVS encodes a viral interleukin, IL-17, which has been shown to support T-cell proliferation and uncontrolled cellular growth by up-regulating NF- $\kappa \mathrm{B}$, and IL-6 expression levels (Yao et al., 1995). HVS-transformed T cells are known to display an elevated expression of cellular IL26, an IL-10-related cytokine that results in STAT1 and STAT3 activation (Hor et al., 2004). Moreover, HVS ORF3 protein, the viral FGARAT-homologous protein, was recently found to induce the proteasomal degradation of the cellular ND10 component Sp100 (Full et al., 2012). A study by Cazalla et al. (2010) showed that viral U-rich non-coding RNAs down-regulate the expression of host miRNA (miR-27), which in turn led to an enhanced IFN$\gamma$ levels in transformed T-cells to promote latency (Cazalla et al., 2010). The group later reported that HVS microRNAs, termed as miR-HSURs, preferentially modulate the expression of host cell cycle regulators (WEE1) and antiviral response factors (MHC-1 complex; Guo et al., 2015).

\section{Rhesus macaque rhadinovirus (RRV)}

Two separate groups identified RRV from rhesus macaques in 1997 (Desrosiers et al., 1997) and 1999 (Wong et al., 1999) at the New England Primate Research Center and Oregon National Primate Research Center, respectively. RRV is a natural pathogen of rhesus macaques (RS) monkey, persists latently in B-lymphocytes, and is known to cause B-cell hyperplasia and persistent lymphadenopathy (Desrosiers et al., 1997; Searles et al., 1999). Genome sequence analysis of RRV 17557, one of the two isolated strains of RRV, revealed a high degree of co-linearity with another rhadinovirus, i.e., KSHV (Searles et al., 1999). The second isolate of RRV, 26-95 also has high degree of similarity with both, KSHV and RRV 17557 (Alexander et al., 2000). Studies focusing on the mechanisms underlying KSHV oncogenesis have been impeded due to the lack of a proper animal model and poor replication of the virus in cell culture. In contrast, RRV grows efficiently in cell culture and produces high titers of virus upon induction, hence serves as an excellent model for studying both the in vivo and in vitro KSHV infection.

\section{Role of RRV Antigens in Cancer Progression by Modulation of Apoptotic Signaling}

Damania's group showed that $\mathrm{R} 1$ protein of RRV bears significant similarity to the $\mathrm{K} 1$ protein of $\mathrm{KSHV}$ and initiates $\mathrm{B}$ lymphocyte activation through its signal transducing cytoplasmic domain, thereby formulates its role as an oncoprotein (Damania et al., 1999, 2000b). RRV, upon co-infection with Simian Immunodeficiency Virus (Sadagopan et al., 2007) has been reported to develop lymphoproliferative disorders, similar to those in AIDS patients, co-infected with KSHV (Wong et al., 1999). RRV is also known to possess viral interleukin-6, RvIL6, which potentially plays a role in RRV pathogenesis by regulating host-virus interactions and possibly enhancing host IL-6 signaling (Kaleeba et al., 1999), hence, assisting in B cell proliferation, both in vivo and in vitro (Kaleeba et al., 1999; Orzechowska et al., 2008). RRV ORF74 has been reported to induce tumor formation in mice and up-regulates VEGF secretion through activation of Erk signaling, resulting in cellular transformation, similar to that caused by ORF74 of KSHV. This confirms that these two proteins are homologous and RRV ORF74 is likely to contribute to RRV-related malignancies in a similar fashion to the KSHV ORF 74 (Estep et al., 2003). Previous studies have reported the reduction in macrophage activation following expression of the protein RRV vCD200, encoded by RRV ORFR15, in vitro (Langlais et al., 2006). In addition, a recent study demonstrated the role of RRV vCD200 in modulation of host immune responses at early times post infection. The RRV vCD200 was found to inhibit excess virus production at early time points in order to promote viral infection. These observations indicate a plausible role of vCD200 in direct inhibition of antigenpresenting cells, through decline in the levels of CD200 receptor on dendritic cells (Estep et al., 2014). Also, RRV encodes for eight vIRF proteins that are viral homologs of the cellular IRFs. These RRV vIRFs were reported to interfere with the transcriptional functions of cellular IRFs and led to a reduction in induction of IFNs post infection. These findings were further supported by the results that demonstrate an increase in the IFN production following deletion of the IRFs (Robinson et al., 2012). According to a recent study, the vIRFs inhibit the IFN gene activation by interacting with $\mathrm{CREB}$ binding protein, $\mathrm{CBP}$, a transcriptional co-activator and acetyltransferase (Morin et al., 2015). These observations account for an important role of IRFs in hampering the host immune response against the virus. In addition, RRV ORF71 encodes a cellular homolog for FLIP (FLICE, FADD-like interleukin-1-converting enzyme-inhibitory protein) known as viral FLIP (vFLIP), during the latent phase of the virus. The $v$ FLIP protein was found to promote cell survival and inhibit apoptosis in latently infected cells through autophagosome formation. The 


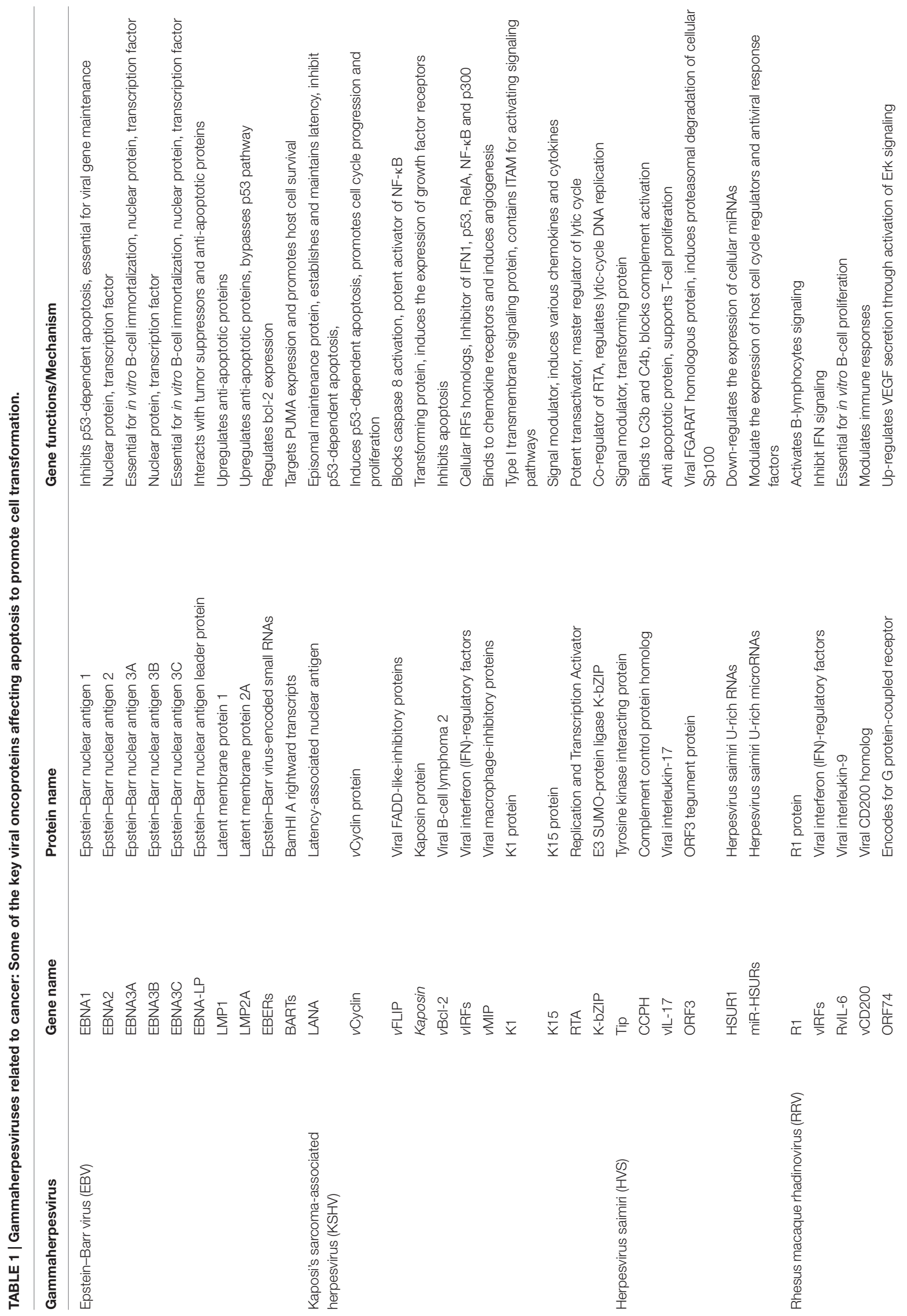


inhibition in $v$ FLIP protein expression resulted in the loss of anti-apoptotic property of the cells and concomitant reduction in autophagy (Ritthipichai et al., 2012).

\section{CONCLUSION}

In summary, the study of tumor viruses has been instrumental to our present knowledge of multiple neoplastic diseases. It is now clear that several $\gamma$-herpesviruses, including, KSHV, EBV, and HVS express a diverse repertoire of viral genes that control the cell's death machinery and contribute to the viral replication and tumor progression in the infected, immuno-compromised hosts at opportune times. These viruses have developed diverse and complex mechanisms to circumvent host-mediated selfdestruction and perturb the cellular control of apoptosis, immune recognition and autophagy to their advantage via the expression of unique viral anti-autophagic and anti-apoptotic proteins, viral homologs of host proteins and activation of a plethora of cellular signaling proteins to promote viral replication and lifelong persistence Table 1. As deregulation of cell signaling pathways is a defining feature of malignantly transformed cells thus, unraveling these mechanisms will definitely delineate new

\section{REFERENCES}

Ablashi, D. V., Levine, P. H., Papas, T., Pearson, G. R., and Kottaridis, S. D. (1985). First international symposium on Epstein-Barr virus and associated malignant diseases. Cancer Res. 45, 3981-3984.

Alexander, L., Denekamp, L., Knapp, A., Auerbach, M. R., Damania, B., and Desrosiers, R. C. (2000). The primary sequence of rhesus monkey rhadinovirus isolate 26-95: sequence similarities to Kaposi's sarcoma-associated herpesvirus and rhesus monkey rhadinovirus isolate 17577. J. Virol. 74, 3388-3398. doi: 10.1128/JVI.74.7.3388-3398.2000

Anderton, E., Yee, J., Smith, P., Crook, T., White, R. E., and Allday, M. J. (2008). Two Epstein-Barr virus (EBV) oncoproteins cooperate to repress expression of the proapoptotic tumour-suppressor Bim: clues to the pathogenesis of Burkitt's lymphoma. Oncogene 27, 421-433. doi: 10.1038/sj.onc.1210668

Ashhab, Y., Alian, A., Polliack, A., Panet, A., and Ben Yehuda, D. (2001) Two splicing variants of a new inhibitor of apoptosis gene with different biological properties and tissue distribution pattern. FEBS Lett. 495, 56-60. doi: 10.1016/S0014-5793(01)02366-3

Avery-Kiejda, K. A., Bowden, N. A., Croft, A. J., Scurr, L. L., Kairupan, C. F., Ashton, K. A., et al. (2011). P53 in human melanoma fails to regulate target genes associated with apoptosis and the cell cycle and may contribute to proliferation. BMC Cancer 11:203. doi: 10.1186/1471-2407-11-203

Babcock, G. J., Hochberg, D., and Thorley-Lawson, A. D. (2000). The expression pattern of Epstein-Barr virus latent genes in vivo is dependent upon the differentiation stage of the infected B cell. Immunity 13, 497-506. doi: 10.1016/S1074-7613(00)00049-2

Ballon, G., Chen, K., Perez, R., Tam, W., and Cesarman, E. (2011). Kaposi sarcoma herpesvirus (KSHV) vFLIP oncoprotein induces B cell transdifferentiation and tumorigenesis in mice. J. Clin. Invest. 121, 1141-1153. doi: 10.1172/JCI44417

Banerjee, S., Lu, J., Cai, Q., Saha, A., Jha, H. C., Dzeng, R. K., et al. (2013). The EBV latent antigen $3 \mathrm{C}$ inhibits apoptosis through targeted regulation of interferon regulatory factors 4 and 8. PLoS Pathog. 9:e1003314. doi: 10.1371/journal.ppat.1003314

Banerjee, S., Lu, J., Cai, Q., Sun, Z., Jha, H. C., and Robertson, E. S. (2014). EBNA3C augments Pim-1 mediated phosphorylation and degradation of p21 to promote B-cell proliferation. PLoS Pathog. 10:e1004304. doi: 10.1371/journal.ppat.1004304 strategies to prevent tumor growth as well as identify causative novel targets suitable for drug development.

\section{AUTHOR CONTRIBUTIONS}

All authors listed, have made substantial, direct and intellectual contribution to the work, and approved it for publication.

\section{FUNDING}

This work was supported from the National Institute of Health (CA174459 and AI105000) and the Research Scholar Grant (124389-RSG-13-230-01-MPC) from the American Cancer Society.

\section{ACKNOWLEDGMENTS}

We sincerely apologize to those authors whose original work could not be cited because of space limitations. The authors also thank lab members for critical review and helpful comments on the manuscript.

Baresova, P., Musilova, J., Pitha, P. M., and Lubyova, B. (2014). p53 tumor suppressor protein stability and transcriptional activity are targeted by Kaposi's sarcoma-associated herpesvirus-encoded viral interferon regulatory factor 3 . Mol. Cell. Biol. 34, 386-399. doi: 10.1128/MCB.01011-13

Baresova, P., Pitha, P. M., and Lubyova, B. (2013). Distinct roles of Kaposi's sarcoma-associated herpesvirus-encoded viral interferon regulatory factors in inflammatory response and cancer. J. Virol. 87, 9398-9410. doi: 10.1128/JVI.03315-12

Bieging, K. T., Amick, A. C., and Longnecker, R. (2009). Epstein-Barr virus LMP2A bypasses p53 inactivation in a MYC model of lymphomagenesis. Proc. Natl. Acad. Sci. U.S.A. 106, 17945-17950. doi: 10.1073/pnas.0907994106

Biesinger, B., Muller-Fleckenstein, I., Simmer, B., Lang, G., Wittmann, S., Platzer, E., et al. (1992). Stable growth transformation of human T lymphocytes by herpesvirus saimiri. Proc. Natl. Acad. Sci. U.S.A. 89, 3116-3119. doi: 10.1073/pnas.89.7.3116

Blacklow, N. R., Watson, B. K., Miller, G., and Jacobson, B. M. (1971). Mononucleosis with heterophil antibodies and EB virus infection. Acquisition by an elderly patient in hospital. Am. J. Med. 51, 549-552. doi: 10.1016/00029343(71)90260-9

Borah, S., Verma, S. C., and Robertson, E. S. (2004). ORF73 of herpesvirus saimiri, a viral homolog of Kaposi's sarcoma-associated herpesvirus, modulates the two cellular tumor suppressor proteins p53 and pRb. J. Virol. 78, 10336-10347. doi: 10.1128/JVI.78.19.10336-10347.2004

Bowser, B. S., Morris, S., Song, M. J., Sun, R., and Damania, B. (2006). Characterization of Kaposi's sarcoma-associated herpesvirus (KSHV) K1 promoter activation by Rta. Virology 348, 309-327. doi: 10.1016/j.virol.2006.02.007

Breckenridge, D. G., Germain, M., Mathai, J. P., Nguyen, M., and Shore, G. C. (2003). Regulation of apoptosis by endoplasmic reticulum pathways. Oncogene 22, 8608-8618. doi: 10.1038/sj.onc. 1207108

Brinkmann, M. M., Glenn, M., Rainbow, L., Kieser, A., Henke-Gendo, C., and Schulz, T. F. (2003). Activation of mitogen-activated protein kinase and NFkappaB pathways by a Kaposi's sarcoma-associated herpesvirus K15 membrane protein. J. Virol. 77, 9346-9358. doi: 10.1128/JVI.77.17.9346-9358.2003

Brinkmann, M. M., Pietrek, M., Dittrich-Breiholz, O., Kracht, M., and Schulz, T. F. (2007). Modulation of host gene expression by the K15 protein of Kaposi's sarcoma-associated herpesvirus. J. Virol. 81, 42-58. doi: 10.1128/JVI.00648-06 
Brown, J. M., and Attardi, L. D. (2005). The role of apoptosis in cancer development and treatment response. Nat. Rev. Cancer 5, 231-237.

Brown, S. B., Bailey, K., and Savill, J. (1997). Actin is cleaved during constitutive apoptosis. Biochem. J. 323(Pt 1), 233-237. doi: 10.1042/bj3230233

Bu, W., Palmeri, D., Krishnan, R., Marin, R., Aris, V. M., Soteropoulos, P., et al. (2008). Identification of direct transcriptional targets of the Kaposi's sarcoma-associated herpesvirus Rta lytic switch protein by conditional nuclear localization. J. Virol. 82, 10709-10723. doi: 10.1128/JVI. 01012-08

Burysek, L., Yeow, W. S., Lubyova, B., Kellum, M., Schafer, S. L., Huang, Y. Q., et al. (1999a). Functional analysis of human herpesvirus 8-encoded viral interferon regulatory factor 1 and its association with cellular interferon regulatory factors and p300. J. Virol. 73, 7334-7342.

Burysek, L., Yeow, W. S., and Pitha, P. M. (1999b). Unique properties of a second human herpesvirus 8-encoded interferon regulatory factor (vIRF-2). J. Hum. Virol. 2, 19-32.

Byun, H., Gwack, Y., Hwang, S., and Choe, J. (2002). Kaposi's sarcoma-associated herpesvirus open reading frame (ORF) 50 transactivates K8 and ORF57 promoters via heterogeneous response elements. Mol. Cells 14, 185-191.

Cai, Q., Banerjee, S., Cervini, A., Lu, J., Hislop, A. D., Dzeng, R., et al. (2013). IRF-4-mediated CIITA transcription is blocked by KSHV encoded LANA to inhibit MHC II presentation. PLoS Pathog. 9:e1003751. doi: 10.1371/journal.ppat.1003751

Cai, Q., Guo, Y., Xiao, B., Banerjee, S., Saha, A., Lu, J., et al. (2011). Epstein-Barr virus nuclear antigen $3 \mathrm{C}$ stabilizes Gemin 3 to block p53-mediated apoptosis. PLoS Pathog. 7:e1002418. doi: 10.1371/journal.ppat.1002418

Cai, X., Schafer, A., Lu, S., Bilello, J. P., Desrosiers, R. C., Edwards, R., et al. (2006). Epstein-Barr virus microRNAs are evolutionarily conserved and differentially expressed. PLoS Pathog. 2:e23. doi: 10.1371/journal.ppat.0020023

Camilleri-Broet, S., Davi, F., Feuillard, J., Bourgeois, C., Seilhean, D., Hauw, J. J., et al. (1995). High expression of latent membrane protein 1 of Epstein-Barr virus and BCL-2 oncoprotein in acquired immunodeficiency syndrome-related primary brain lymphomas. Blood $86,432-435$.

Campion, E. M., Hakimjavadi, R., Loughran, S. T., Phelan, S., Smith, S. M., D’souza, B. N., et al. (2014). Repression of the proapoptotic cellular BIK/NBK gene by Epstein-Barr virus antagonizes transforming growth factor beta1-induced B-cell apoptosis. J. Virol. 88, 5001-5013. doi: 10.1128/JVI.03642-13

Cazalla, D., Yario, T., and Steitz, J. A. (2010). Down-regulation of a host microRNA by a Herpesvirus saimiri noncoding RNA. Science 328, 1563-1566. doi: $10.1126 /$ science. 1187197

Cesarman, E., Chang, Y., Moore, P. S., Said, J. W., and Knowles, D. M. (1995). Kaposi's sarcoma-associated herpesvirus-like DNA sequences in AIDSrelated body-cavity-based lymphomas. N. Engl. J. Med. 332, 1186-1191. doi: 10.1056/NEJM199505043321802

Chakraborty, J., Banerjee, S., Ray, P., Hossain, D. M., Bhattacharyya, S., Adhikary, A., et al. (2010). Gain of cellular adaptation due to prolonged p53 impairment leads to functional switchover from p53 to p73 during DNA damage in acute myeloid leukemia cells. J. Biol. Chem. 285, 33104-33112. doi: 10.1074/jbc.M110.122705

Chang, P. C., Cheng, C. Y., Campbell, M., Yang, Y. C., Hsu, H. W., Chang, T. Y., et al. (2013). The chromatin modification by SUMO-2/3 but not SUMO1 prevents the epigenetic activation of key immune-related genes during Kaposi's sarcoma associated herpesvirus reactivation. BMC Genomics 14:824. doi: 10.1186/1471-2164-14-824

Chang, P. C., Izumiya, Y., Wu, C. Y., Fitzgerald, L. D., Campbell, M., Ellison, T. J., et al. (2010). Kaposi's sarcoma-associated herpesvirus (KSHV) encodes a SUMO E3 ligase that is SIM-dependent and SUMO-2/3-specific. J. Biol. Chem. 285, 5266-5273. doi: 10.1074/jbc.M109.088088

Chang, Y., Cesarman, E., Pessin, M. S., Lee, F., Culpepper, J., Knowles, D. M., et al. (1994). Identification of herpesvirus-like DNA sequences in AIDS-associated Kaposi's sarcoma. Science 266, 1865-1869. doi: 10.1126/science.7997879

Chao, M., Wang, H. N., Lu, Y. J., Chang, Y. S., and Yu, J. S. (2014). The V-val subtype Epstein-Barr virus nuclear antigen 1 promotes cell survival after serum withdrawal. Oncol. Rep. 33, 958-966. doi: 10.3892/or.2014.3625

Chen, A., Divisconte, M., Jiang, X., Quink, C., and Wang, F. (2005). Epstein-Barr virus with the latent infection nuclear antigen $3 \mathrm{~B}$ completely deleted is still competent for B-cell growth transformation in vitro. J. Virol. 79, 4506-4509. doi: 10.1128/JVI.79.7.4506-4509.2005
Chen, Z., Naito, M., Hori, S., Mashima, T., Yamori, T., and Tsuruo, T. (1999). A human IAP-family gene, apollon, expressed in human brain cancer cells. Biochem. Biophys. Res. Commun. 264, 847-854. doi: 10.1006/bbrc.1999.1585

Cheng, E. H.-Y., Nicholas, J., Bellows, D. S., Hayward, G. S., Guo, H.-G., Reitz, M. S., et al. (1997). A Bcl-2 homolog encoded by Kaposi sarcoma-associated virus, human herpesvirus 8 , inhibits apoptosis but does not heterodimerize with Bax or?Bak. Proc. Natl. Acad. Sci. U.S.A. 94, 690-694. doi: 10.1073/pnas.94.2.690

Cheng, T. C., Hsieh, S. S., Hsu, W. L., Chen, Y. F., Ho, H. H., and Sheu, L. F. (2009). Expression of Epstein-Barr nuclear antigen 1 in gastric carcinoma cells is associated with enhanced tumorigenicity and reduced cisplatin sensitivity. Int. J. Oncol. 36, 151-160.

Cho, N. H., Choi, Y. K., and Choi, J. K. (2008). Multi-transmembrane protein K15 of Kaposi's sarcoma-associated herpesvirus targets Lyn kinase in the membrane raft and induces NFAT/AP1 activities. Exp. Mol. Med. 40, 565-573. doi: 10.3858/emm.2008.40.5.565

Cho, N. H., Feng, P., Lee, S. H., Lee, B. S., Liang, X., Chang, H., et al. (2004). Inhibition of $\mathrm{T}$ cell receptor signal transduction by tyrosine kinaseinteracting protein of Herpesvirus saimiri. J. Exp. Med. 200, 681-687. doi: 10.1084/jem.20040924

Cho, N. H., Kingston, D., Chang, H., Kwon, E. K., Kim, J. M., Lee, J. H., et al. (2006). Association of herpesvirus saimiri tip with lipid raft is essential for downregulation of T-cell receptor and CD4 coreceptor. J. Virol. 80, 108-118. doi: 10.1128/JVI.80.1.108-118.2006

Cho, Y. G., Gordadze, A. V., Ling, P. D., and Wang, F. (1999). Evolution of two types of rhesus lymphocryptovirus similar to type 1 and type 2 Epstein-Barr virus. J. Virol. 73, 9206-9212.

Choi, J. K., Lee, B. S., Shim, S. N., Li, M., and Jung, J. U. (2000). Identification of the novel K15 gene at the rightmost end of the Kaposi's sarcoma-associated herpesvirus genome. J. Virol. 74, 436-446. doi: 10.1128/JVI.74.1.436-446.2000

Chow, W. A., Fang, J. J., and Yee, J. K. (2000). The IFN regulatory factor family participates in regulation of Fas ligand gene expression in T cells. J. Immunol. 164, 3512-3518. doi: 10.4049/jimmunol.164.7.3512

Choy, E. Y., Siu, K. L., Kok, K. H., Lung, R. W., Tsang, C. M., To, K. F., et al. (2008). An Epstein-Barr virus-encoded microRNA targets PUMA to promote host cell survival. J. Exp. Med. 205, 2551-2560. doi: 10.1084/jem.20072581

Collavin, L., Lunardi, A., and Del Sal, G. (2010). p53-family proteins and their regulators: hubs and spokes in tumor suppression. Cell Death. Differ. 17, 901-911. doi: 10.1038/cdd.2010.35

Cooper, A., Johannsen, E., Maruo, S., Cahir-Mcfarland, E., Illanes, D., Davidson, D., et al. (2003). EBNA3A association with RBP-Jkappa down-regulates c-myc and Epstein-Barr virus-transformed lymphoblast growth. J. Virol. 77, 999-1010. doi: 10.1128/JVI.77.2.999-1010.2003

Damania, B. (2004). Oncogenic gamma-herpesviruses: comparison of viral proteins involved in tumorigenesis. Nat. Rev. Microbiol. 2, 656-668. doi: 10.1038/nrmicro958

Damania, B., Choi, J. K., and Jung, J. U. (2000a). Signaling activities of gammaherpesvirus membrane proteins. J. Virol. 74, 1593-1601. doi: 10.1128/JVI.74.4.1593-1601.2000

Damania, B., Demaria, M., Jung, J. U., and Desrosiers, R. C. (2000b). Activation of lymphocyte signaling by the R1 protein of rhesus monkey rhadinovirus. J. Virol. 74, 2721-2730. doi: 10.1128/JVI.74.6.2721-2730.2000

Damania, B., Li, M., Choi, J.-K., Alexander, L., Jung, J. U., and Desrosiers, R. C. (1999). Identification of the R1 oncogene and Its protein product from the rhadinovirus of rhesus monkeys. J. Virol. 73, 5123-5131.

Danial, N. N., and Korsmeyer, S. J. (2004). Cell death: critical control points. Cell 116, 205-219. doi: 10.1016/S0092-8674(04)00046-7

Deng, H., Song, M. J., Chu, J. T., and Sun, R. (2002). Transcriptional regulation of the interleukin- 6 gene of human herpesvirus 8 (Kaposi's sarcoma-associated herpesvirus). J. Virol. 76, 8252-8264. doi: 10.1128/JVI.76.16.8252-8264.2002

Desrosiers, R. C., Sasseville, V. G., Czajak, S. C., Zhang, X., Mansfield, K. G., Kaur, A., et al. (1997). A herpesvirus of rhesus monkeys related to the human Kaposi's sarcoma-associated herpesvirus. J. Virol. 71, 9764-9769.

Devarajan, E., Sahin, A. A., Chen, J. S., Krishnamurthy, R. R., Aggarwal, N., Brun, A. M., et al. (2002). Down-regulation of caspase 3 in breast cancer: a possible mechanism for chemoresistance. Oncogene 21, 8843-8851. doi: 10.1038/sj.onc. 1206044

Dheekollu, J., Chen, H. S., Kaye, K. M., and Lieberman, P. M. (2013). Timelessdependent DNA replication-coupled recombination promotes Kaposi's 
Sarcoma-associated herpesvirus episome maintenance and terminal repeat stability. J. Virol. 87, 3699-3709. doi: 10.1128/JVI.02211-12

Dheekollu, J., and Lieberman, P. M. (2011). The replisome pausing factor timeless is required for episomal maintenance of latent Epstein-Barr virus. J. Virol. 85, 5853-5863. doi: 10.1128/JVI.02425-10

Dirmeier, U., Hoffmann, R., Kilger, E., Schultheiss, U., Briseno, C., Gires, O., et al. (2005). Latent membrane protein 1 of Epstein-Barr virus coordinately regulates proliferation with control of apoptosis. Oncogene 24, 1711-1717. doi: 10.1038/sj.onc. 1208367

Dotsch, V., Bernassola, F., Coutandin, D., Candi, E., and Melino, G. (2010). p63 and p73, the ancestors of p53. Cold Spring Harb. Perspect. Biol. 2:a004887. doi: 10.1101/cshperspect.a004887

Du, M. Q., Diss, T. C., Liu, H., Ye, H., Hamoudi, R. A., Cabecadas, J., et al. (2002). KSHV- and EBV-associated germinotropic lymphoproliferative disorder. Blood 100, 3415-3418. doi: 10.1182/blood-2002-02-0487

Dufva, M., Olsson, M., and Rymo, L. (2001). Epstein-Barr virus nuclear antigen 5 interacts with HAX-1, a possible component of the B-cell receptor signalling pathway. J. Gen. Virol. 82, 1581-1587. doi: 10.1099/0022-1317-82-7-1581

Dunkel, V. C., Pry, T. W., Henle, G., and Henle, W. (1972). Immunofluorescence tests for antibodies to Epstein-Barr virus with sera of lower primates. J. Natl. Cancer Inst. 49, 435-440.

Ellis, M., Chew, Y. P., Fallis, L., Freddersdorf, S., Boshoff, C., Weiss, R. A., et al. (1999). Degradation of p27 (Kip) cdk inhibitor triggered by Kaposi's sarcoma virus cyclin-cdk6 complex. EMBO J. 18, 644-653. doi: 10.1093/emboj/18.3.644

Endres, M. J., Garlisi, C. G., Xiao, H., Shan, L., and Hedrick, J. A. (1999). The Kaposi's sarcoma-related herpesvirus (KSHV)-encoded chemokine vMIP-I is a specific agonist for the CC chemokine receptor (CCR)8. J. Exp. Med. 189, 1993-1998. doi: 10.1084/jem.189.12.1993

Estep, R. D., Axthelm, M. K., and Wong, S. W. (2003). A G proteincoupled receptor encoded by rhesus rhadinovirus is similar to ORF74 of Kaposi's sarcoma-associated herpesvirus. J. Virol. 77, 1738-1746. doi: 10.1128/JVI.77.3.1738-1746.2003

Estep, R. D., Rawlings, S. D., Li, H., Manoharan, M., Blaine, E. T., O'connor, M. A., et al. (2014). The rhesus rhadinovirus CD200 homologue affects immune responses and viral loads during in vivo infection. J. Virol. 88, 10635-10654. doi: 10.1128/JVI.01276-14

Ewald, P. W. (2010). 99th Dahlem conference on infection, inflammation and chronic inflammatory disorders: symbionts and immunopathology in chronic diseases: insights from evolution. Clin. Exp. Immunol. 160, 27-34. doi: 10.1111/j.1365-2249.2010.04127.x

Fernald, K., and Kurokawa, M. (2013). Evading apoptosis in cancer. Trends Cell Biol. 23, 620-633. doi: 10.1016/j.tcb.2013.07.006

Fickenscher, H., and Fleckenstein, B. (2001). Herpesvirus saimiri. Philos. Trans. R. Soc. Lond. B Biol. Sci. 356, 545-567. doi: 10.1098/rstb.2000.0780

Fink, S. L., and Cookson, B. T. (2005). Apoptosis, pyroptosis, and necrosis: mechanistic description of dead and dying eukaryotic cells. Infect. Immun. 73, 1907-1916. doi: 10.1128/IAI.73.4.1907-1916.2005

Finke, J., Fritzen, R., Ternes, P., Trivedi, P., Bross, K. J., Lange, W., et al. (1992). Expression of bcl-2 in Burkitt's lymphoma cell lines: induction by latent Epstein-Barr virus genes. Blood 80, 459-469.

Flanagan, A. M., and Letai, A. (2008). BH3 domains define selective inhibitory interactions with BHRF-1 and KSHV BCL-2. Cell Death. Differ. 15, 580-588. doi: 10.1038/sj.cdd.4402292

Fong, P. Y., Xue, W. C., Ngan, H. Y., Chiu, P. M., Chan, K. Y., Tsao, S. W., et al. (2006). Caspase activity is downregulated in choriocarcinoma: a cDNA array differential expression study. J. Clin. Pathol. 59, 179-183. doi: $10.1136 /$ jcp.2005.028027

Frappier, L. (2012). Contributions of Epstein-Barr nuclear antigen 1 (EBNA1) to cell immortalization and survival. Viruses 4, 1537-1547. doi: 10.3390/ v4091537

Friborg, J. Jr., Kong, W., Hottiger, M. O., and Nabel, G. J. (1999). p53 inhibition by the LANA protein of KSHV protects against cell death. Nature 402, 889-894.

Fritz, J. H., Ferrero, R. L., Philpott, D. J., and Girardin, S. E. (2006). Nod-like proteins in immunity, inflammation and disease. Nat. Immunol. 7, 1250-1257. doi: $10.1038 /$ nil 1412

$\mathrm{Fu}, \mathrm{Q} ., \mathrm{He}, \mathrm{C}$, and Mao, Z. R. (2013). Epstein-Barr virus interactions with the Bcl-2 protein family and apoptosis in human tumor cells. J. Zhejiang Uni. Sci. B 14, 8-24. doi: 10.1631/jzus.B1200189
Fuentes-Gonzalez, A. M., Contreras-Paredes, A., Manzo-Merino, J., and Lizano, M. (2013). The modulation of apoptosis by oncogenic viruses. Virol. J. 10, 182. doi: $10.1186 / 1743-422 X-10-182$

Fujimuro, M., Wu, F. Y., Aprhys, C., Kajumbula, H., Young, D. B., Hayward, G. S., et al. (2003). A novel viral mechanism for dysregulation of beta-catenin in Kaposi's sarcoma-associated herpesvirus latency. Nat. Med. 9, 300-306. doi: $10.1038 / \mathrm{nm} 829$

Fulda, S. (2010). Evasion of apoptosis as a cellular stress response in cancer. Int. J. Cell Biol. 2010:370835. doi: 10.1155/2010/370835

Fulda, S., Meyer, E., and Debatin, K. M. (2002). Inhibition of TRAILinduced apoptosis by Bcl-2 overexpression. Oncogene 21, 2283-2294. doi: 10.1038/sj.onc.1205258

Full, F., Reuter, N., Zielke, K., Stamminger, T., and Ensser, A. (2012). Herpesvirus saimiri antagonizes nuclear domain 10-instituted intrinsic immunity via an ORF3-mediated selective degradation of cellular protein Sp100. J. Virol. 86, 3541-3553. doi: 10.1128/JVI.06992-11

Ganem, D. (2006). KSHV infection and the pathogenesis of Kaposi's sarcoma. Annu. Rev. Pathol. 1, 273-296. doi: 10.1146/annurev.pathol.1.110304.100133

Gao, J., Cai, Q., Lu, J., Jha, H. C., and Robertson, E. S. (2011). Upregulation of cellular Bcl-2 by the KSHV encoded RTA promotes virion production. PLoS ONE 6:e23892. doi: 10.1371/journal.pone.0023892

Garibal, J., Hollville, E., Bell, A. I., Kelly, G. L., Renouf, B., Kawaguchi, Y., et al. (2007). Truncated form of the Epstein-Barr virus protein EBNA-LP protects against caspase-dependent apoptosis by inhibiting protein phosphatase $2 \mathrm{~A}$. J. Virol. 81, 7598-7607. doi: 10.1128/JVI.02435-06

Gennart, I., Coupeau, D., Pejakovic, S., Laurent, S., Rasschaert, D., and Muylkens, B. (2015). Marek's disease: genetic regulation of gallid herpesvirus 2 infection and latency. Vet. J. 205, 339-348. doi: 10.1016/j.tvjl.2015. 04.038

Gessain, A., Sudaka, A., Briere, J., Fouchard, N., Nicola, M. A., Rio, B., et al. (1996). Kaposi sarcoma-associated herpes-like virus (human herpesvirus type 8) DNA sequences in multicentric Castleman's disease: is there any relevant association in non-human immunodeficiency virus-infected patients? Blood 87, 414-416.

Ghobrial, I. M., Witzig, T. E., and Adjei, A. A. (2005). Targeting apoptosis pathways in cancer therapy. CA Cancer J. Clin. 55, 178-194. doi: 10.3322/canjclin.55.3.178

Glenn, M., Rainbow, L., Aurade, F., Davison, A., and Schulz, T. F. (1999). Identification of a spliced gene from Kaposi's sarcoma-associated herpesvirus encoding a protein with similarities to latent membrane proteins 1 and $2 \mathrm{~A}$ of Epstein-Barr virus. J. Virol. 73, 6953-6963.

Godden-Kent, D., Talbot, S. J., Boshoff, C., Chang, Y., Moore, P., Weiss, R. A., et al. (1997). The cyclin encoded by Kaposi's sarcoma-associated herpesvirus stimulates cdk6 to phosphorylate the retinoblastoma protein and histone H1. J. Virol. 71, 4193-4198.

Goolsby, C., Paniagua, M., Tallman, M., and Gartenhaus, R. B. (2005). Bcl-2 regulatory pathway is functional in chronic lymphocytic leukemia. Cytometry B Clin. Cytom. 63, 36-46. doi: 10.1002/cyto.b.20034

Gottwein, E., and Cullen, B. R. (2008). Viral and cellular microRNAs as determinants of viral pathogenesis and immunity. Cell Host Microbe 3, 375-387. doi: 10.1016/j.chom.2008.05.002

Gould, F., Harrison, S. M., Hewitt, E. W., and Whitehouse, A. (2009). Kaposi's sarcoma-associated herpesvirus RTA promotes degradation of the Heyl repressor protein through the ubiquitin proteasome pathway. J. Virol. 83, 6727-6738. doi: 10.1128/JVI.00351-09

Gross, A., Mcdonnell, J. M., and Korsmeyer, S. J. (1999). BCL-2 family members and the mitochondria in apoptosis. Genes Dev. 13, 1899-1911. doi: 10.1101/gad.13.15.1899

Grundhoff, A., Sullivan, C. S., and Ganem, D. (2006). A combined computational and microarray-based approach identifies novel microRNAs encoded by human gamma-herpesviruses. RNA 12, 733-750. doi: 10.1261/rna.2326106

Guasparri, I., Keller, S. A., and Cesarman, E. (2004). KSHV vFLIP is essential for the survival of infected lymphoma cells. J. Exp. Med. 199, 993-1003. doi: 10.1084/jem.20031467

Guo, Y. E., Oei, T., and Steitz, J. A. (2015). Herpesvirus saimiri MicroRNAs preferentially target host cell cycle regulators. J. Virol. 89, 10901-10911. doi: 10.1128/JVI.01884-15

Han, I., Harada, S., Weaver, D., Xue, Y., Lane, W., Orstavik, S., et al. (2001). EBNALP associates with cellular proteins including DNA-PK and HA95. J. Virol. 75, 2475-2481. doi: 10.1128/JVI.75.5.2475-2481.2001 
Hengartner, M. O. (2000). The biochemistry of apoptosis. Nature 407, 770-776. doi: $10.1038 / 35037710$

Hengartner, M. O. (2001). Apoptosis: corralling the corpses. Cell 104, 325-328. doi: 10.1016/S0092-8674(01)00219-7

Hor, S., Pirzer, H., Dumoutier, L., Bauer, F., Wittmann, S., Sticht, H., et al. (2004). The T-cell lymphokine interleukin-26 targets epithelial cells through the interleukin-20 receptor 1 and interleukin-10 receptor 2 chains. J. Biol. Chem. 279, 33343-33351. doi: 10.1074/jbc.M405000200

Hume, A. J., and Kalejta, R. F. (2009). Regulation of the retinoblastoma proteins by the human herpesviruses. Cell Div. 4, 1. doi: 10.1186/1747-1028-4-1

Iizasa, H., Nanbo, A., Nishikawa, J., Jinushi, M., and Yoshiyama, H. (2012). Epstein-Barr Virus (EBV)-associated gastric carcinoma. Viruses 4, 3420-3439. doi: 10.3390/v4123420

Izumiya, Y., Kobayashi, K., Kim, K. Y., Pochampalli, M., Izumiya, C., Shevchenko, B., et al. (2013). Kaposi's sarcoma-associated herpesvirus K-Rta exhibits SUMO-targeting ubiquitin ligase (STUbL) like activity and is essential for viral reactivation. PLoS Pathog. 9:e1003506. doi: 10.1371/journal.ppat.1003506

Izumiya, Y., Lin, S. F., Ellison, T., Chen, L. Y., Izumiya, C., Luciw, P., et al. (2003). Kaposi's sarcoma-associated herpesvirus K-bZIP is a coregulator of K-Rta: physical association and promoter-dependent transcriptional repression. J. Virol. 77, 1441-1451. doi: 10.1128/JVI.77.2.1441-1451.2003

Jacobs, S. R., and Damania, B. (2011). The viral interferon regulatory factors of KSHV: immunosuppressors or oncogenes? Front. Immunol. 2:19. doi: 10.3389/fimmu.2011.00019

Jacobs, S. R., Gregory, S. M., West, J. A., Wollish, A. C., Bennett, C. L., Blackbourn, D. J., et al. (2013). The viral interferon regulatory factors of kaposi's sarcoma-associated herpesvirus differ in their inhibition of interferon activation mediated by toll-like receptor 3. J. Virol. 87, 798-806. doi: 10.1128/JVI. 01851-12

Jarviluoma, A., Koopal, S., Rasanen, S., Makela, T. P., and Ojala, P. M. (2004). KSHV viral cyclin binds to p27KIP1 in primary effusion lymphomas. Blood 104, 3349-3354. doi: 10.1182/blood-2004-05-1798

Jha, H. C., Lu, J., Saha, A., Cai, Q., Banerjee, S., Prasad, M. A., et al. (2013a). EBNA3C-mediated regulation of aurora kinase B contributes to Epstein-Barr virus-induced B-cell proliferation through modulation of the activities of the retinoblastoma protein and apoptotic caspases. J. Virol. 87, 12121-12138. doi: 10.1128/JVI.02379-13

Jha, H. C., Upadhyay, S. K., A J Prasad, M., Lu, J., Cai, Q., Saha, A., et al. (2013b). H2AX phosphorylation is important for LANA-mediated Kaposi's sarcoma-associated herpesvirus episome persistence. J. Virol. 87, 5255-5269. doi: 10.1128/JVI.03575-12

Jung, J. U., Lang, S. M., Friedrich, U., Jun, T., Roberts, T. M., Desrosiers, R. C., et al. (1995). Identification of Lck-binding elements in tip of herpesvirus saimiri. J. Biol. Chem. 270, 20660-20667. doi: 10.1074/jbc.270.35. 20660

Kaghad, M., Bonnet, H., Yang, A., Creancier, L., Biscan, J. C., Valent, A., et al. (1997). Monoallelically expressed gene related to p53 at $1 \mathrm{p} 36$, a region frequently deleted in neuroblastoma and other human cancers. Cell 90, 809-819. doi: 10.1016/S0092-8674(00) 80540-1

Kaleeba, J. A., Bergquam, E. P., and Wong, S. W. (1999). A rhesus macaque rhadinovirus related to Kaposi's sarcoma-associated herpesvirus/human herpesvirus 8 encodes a functional homologue of interleukin-6. J. Virol. 73, 6177-6181.

Kang, M. S., and Kieff, E. (2015). Epstein-Barr virus latent genes. Exp. Mol. Med. 47, e131. doi: 10.1038/emm.2014.84

Kashuba, E., Yurchenko, M., Szirak, K., Stahl, J., Klein, G., and Szekely, L. (2005). Epstein-Barr virus-encoded EBNA-5 binds to Epstein-Barr virus-induced Fte1/S3a protein. Exp. Cell Res. 303, 47-55.

Kato-Noah, T., Xu, Y., Rossetto, C. C., Colletti, K., Papouskova, I., and Pari, G. S. (2007). Overexpression of the kaposi's sarcoma-associated herpesvirus transactivator K-Rta can complement a K-bZIP deletion BACmid and yields an enhanced growth phenotype. J. Virol. 81, 13519-13532. doi: 10.1128/JVI.00832-07

Katsch, K., De Jong, S. J., Albrecht, J. C., Steger, J., Genth, H., Posern, G., et al. (2012). Actin-dependent activation of serum response factor in $\mathrm{T}$ cells by the viral oncoprotein tip. Cell Commun. Signal. 10, 5. doi: 10.1186/1478-811X-10-5
Kawaguchi, Y., Nakajima, K., Igarashi, M., Morita, T., Tanaka, M., Suzuki, M., et al. (2000). Interaction of Epstein-Barr virus nuclear antigen leader protein (EBNA-LP) with HS1-associated protein X-1: implication of cytoplasmic function of EBNA-LP. J. Virol. 74, 10104-10111. doi: 10.1128/JVI.74.21.1010410111.2000

Kennedy, G., Komano, J., and Sugden, B. (2003). Epstein-Barr virus provides a survival factor to Burkitt's lymphomas. Proc. Natl. Acad. Sci. U.S.A. 100, 14269-14274. doi: 10.1073/pnas.2336099100

Kim, J. H., Kim, W. S., and Park, C. (2012). Epstein-Barr virus latent membrane protein-1 protects B-cell lymphoma from rituximab-induced apoptosis through miR-155-mediated Akt activation and up-regulation of Mcl-1. Leuk. Lymphoma 53, 1586-1591. doi: 10.3109/10428194.2012.659736

Kim, Y., Kwon, E. K., Jeon, J. H., So, I., Kim, I. G., Choi, M. S., et al. (2012). Activation of the STAT6 transcription factor in Jurkat T-cells by the herpesvirus saimiri Tip protein. J. Gen. Virol. 93, 330-340. doi: 10.1099/vir.0. 036087-0

Kingston, D., Chang, H., Ensser, A., Lee, H. R., Lee, J., Lee, S. H., et al. (2011). Inhibition of retromer activity by herpesvirus saimiri tip leads to CD4 downregulation and efficient T cell transformation. J. Virol. 85, 10627-10638. doi: 10.1128/JVI.00757-11

Klein, G. (1972). Herpesviruses and oncogenesis. Proc. Natl. Acad. Sci. U.S.A. 69, 1056-1064. doi: 10.1073/pnas.69.4.1056

Kliche, S., Nagel, W., Kremmer, E., Atzler, C., Ege, A., Knorr, T., et al. (2001). Signaling by human herpesvirus 8 kaposin A through direct membrane recruitment of cytohesin-1. Mol. Cell. 7, 833-843. doi: 10.1016/S10972765(01)00227-1

Knight, J. S., Sharma, N., Kalman, D. E., and Robertson, E. S. (2004). A cyclinbinding motif within the amino-terminal homology domain of EBNA3C binds cyclin A and modulates cyclin A-dependent kinase activity in Epstein-Barr virus-infected cells. J. Virol. 78, 12857-12867. doi: 10.1128/JVI.78.23.1285712867.2004

Knight, J. S., Sharma, N., and Robertson, E. S. (2005). SCFSkp2 complex targeted by Epstein-Barr virus essential nuclear antigen. Mol. Cell. Biol. 25, 1749-1763. doi: 10.1128/MCB.25.5.1749-1763.2005

Kohlhof, H., Hampel, F., Hoffmann, R., Burtscher, H., Weidle, U. H., Holzel, M., et al. (2009). Notch1, Notch2, and Epstein-Barr virus-encoded nuclear antigen 2 signaling differentially affects proliferation and survival of Epstein-Barr virusinfected B cells. Blood 113, 5506-5515. doi: 10.1182/blood-2008-11-190090

Komano, J., Maruo, S., Kurozumi, K., Oda, T., and Takada, K. (1999). Oncogenic role of Epstein-Barr virus-encoded RNAs in Burkitt's lymphoma cell line Akata. J. Virol. 73, 9827-9831.

Kothakota, S., Azuma, T., Reinhard, C., Klippel, A., Tang, J., Chu, K., et al. (1997). Caspase-3-generated fragment of gelsolin: effector of morphological change in apoptosis. Science 278, 294-298. doi: 10.1126/science.278.5336.294

Krepela, E., Dankova, P., Moravcikova, E., Krepelova, A., Prochazka, J., Cermak, J., et al. (2009). Increased expression of inhibitor of apoptosis proteins, survivin and XIAP, in non-small cell lung carcinoma. Int. J. Oncol. 35, 1449-1462. doi: 10.3892/ijo_00000464

Krithivas, A., Young, D. B., Liao, G., Greene, D., and Hayward, S. D. (2000). Human herpesvirus 8 LANA interacts with proteins of the $\mathrm{mSin} 3$ corepressor complex and negatively regulates Epstein-Barr virus gene expression in dually infected PEL cells. J. Virol. 74, 9637-9645. doi: 10.1128/JVI.74.20.9637-9645.2000

Kroemer, G., El-Deiry, W. S., Golstein, P., Peter, M. E., Vaux, D., Vandenabeele, P., et al. (2005). Classification of cell death: recommendations of the nomenclature committee on cell death. Cell Death. Differ. 12(Suppl. 2), 1463-1467. doi: $10.1038 /$ sj.cdd.4401724

Kroemer, G., Galluzzi, L., and Brenner, C. (2007). Mitochondrial membrane permeabilization in cell death. Physiol. Rev. 87, 99-163. doi: 10.1152/physrev.00013.2006

Kruidering, M., and Evan, G. I. (2000). Caspase-8 in apoptosis: the beginning of "the end?" IUBMB Life 50, 85-90. doi: 10.1080/713803693

Kutok, J. L., and Wang, F. (2006). Spectrum of Epstein-Barr virus-associated diseases. Annu. Rev. Pathol. 1, 375-404. doi: 10.1146/annurev.pathol.1.110304.100209

Kwun, H. J., Da Silva, S. R., Qin, H., Ferris, R. L., Tan, R., Chang, Y., et al. (2011). The central repeat domain 1 of Kaposi's sarcoma-associated herpesvirus (KSHV) latency associated-nuclear antigen 1 (LANA1) prevents cis MHC class I peptide presentation. Virology 412, 357-365. doi: 10.1016/j.virol.2011.01.026 
LaCasse, E. C., Mahoney, D. J., Cheung, H. H., Plenchette, S., Baird, S., and Korneluk, R. G. (2008). IAP-targeted therapies for cancer. Oncogene 27, 62526275. doi: 10.1038/onc.2008.302

Lagunoff, M., Majeti, R., Weiss, A., and Ganem, D. (1999). Deregulated signal transduction by the $\mathrm{K} 1$ gene product of Kaposi's sarcomaassociated herpesvirus. Proc. Natl. Acad. Sci. U.S.A. 96, 5704-5709. doi: 10.1073/pnas.96.10.5704

Lan, K., Kuppers, D. A., and Robertson, E. S. (2005). Kaposi’s sarcoma-associated herpesvirus reactivation is regulated by interaction of latency-associated nuclear antigen with recombination signal sequence-binding protein Jkappa, the major downstream effector of the Notch signaling pathway. J. Virol. 79, 3468-3478. doi: 10.1128/JVI.79.6.3468-3478.2005

Lan, K., Kuppers, D. A., Verma, S. C., and Robertson, E. S. (2004). Kaposi's sarcoma-associated herpesvirus-encoded latency-associated nuclear antigen inhibits lytic replication by targeting Rta: a potential mechanism for virus-mediated control of latency. J. Virol. 78, 6585-6594. doi: 10.1128/JVI.78.12.6585-6594.2004

Lane, D. P. (1992). Cancer. p53, guardian of the genome. Nature 358, 15-16. doi: $10.1038 / 358015 \mathrm{a} 0$

Langlais, C. L., Jones, J. M., Estep, R. D., and Wong, S. W. (2006). Rhesus rhadinovirus R15 encodes a functional homologue of human CD200. J. Virol. 80, 3098-3103. doi: 10.1128/JVI.80.6.3098-3103.2006

Larochelle, B., Flamand, L., Gourde, P., Beauchamp, D., and Gosselin, J. (1998). Epstein-Barr virus infects and induces apoptosis in human neutrophils. Blood 92, 291-299.

Lavrik, I., Golks, A., and Krammer, P. H. (2005). Death receptor signaling. J. Cell Sci. 118, 265-267. doi: 10.1242/jcs.01610

Lavrik, I. N., Golks, A., and Krammer, P. H. (2005). Caspases: pharmacological manipulation of cell death. J. Clin. Invest. 115, 2665-2672. doi: 10.1172/JCI26252

Le Clorennec, C., Youlyouz-Marfak, I., Adriaenssens, E., Coll, J., Bornkamm, G. W., and Feuillard, J. (2006). EBV latency III immortalization program sensitizes B cells to induction of CD95-mediated apoptosis via LMP1: role of NF-kappaB, STAT1, and p53. Blood 107, 2070-2078. doi: 10.1182/blood-200505-2053

Lee, B. S., Connole, M., Tang, Z., Harris, N. L., and Jung, J. U. (2003). Structural analysis of the Kaposi's sarcoma-associated herpesvirus K1 protein. J. Virol. 77, 8072-8086. doi: 10.1128/JVI.77.14.8072-8086.2003

Lee, B. S., Lee, S. H., Feng, P., Chang, H., Cho, N. H., and Jung, J. U. (2005). Characterization of the Kaposi's sarcoma-associated herpesvirus K1 signalosome. J. Virol. 79, 12173-12184. doi: 10.1128/JVI.79.19.1217312184.2005

Lee, H., Guo, J., Li, M., Choi, J. K., Demaria, M., Rosenzweig, M., et al. (1998a). Identification of an immunoreceptor tyrosine-based activation motif of K1 transforming protein of Kaposi's sarcoma-associated herpesvirus. Mol. Cell. Biol. 18, 5219-5228. doi: 10.1128/MCB.18.9.5219

Lee, H., Veazey, R., Williams, K., Li, M., Guo, J., Neipel, F., et al. (1998b). Deregulation of cell growth by the K1 gene of Kaposi's sarcoma-associated herpesvirus. Nat. Med. 4, 435-440. doi: 10.1038/ nm0498-435

Lee, J. M., Lee, K. H., Weidner, M., Osborne, B. A., and Hayward, S. D. (2002). Epstein-Barr virus EBNA2 blocks Nur77-mediated apoptosis. Proc. Natl. Acad. Sci. U.S.A. 99, 11878-11883. doi: 10.1073/pnas.182552499

Lee, J. S., Li, Q., Lee, J. Y., Lee, S. H., Jeong, J. H., Lee, H. R., et al. (2009). FLIP-mediated autophagy regulation in cell death control. Nat. Cell Biol. 11, 1355-1362. doi: $10.1038 /$ ncb1980

Lefort, S., and Flamand, L. (2009). Kaposi's sarcoma-associated herpesvirus K-bZIP protein is necessary for lytic viral gene expression, DNA replication, and virion production in primary effusion lymphoma cell lines. J. Virol. 83, 5869-5880. doi: 10.1128/JVI.01821-08

Lefort, S., Gravel, A., and Flamand, L. (2010). Repression of interferonalpha stimulated genes expression by Kaposi's sarcoma-associated herpesvirus K-bZIP protein. Virology 408, 14-30. doi: 10.1016/j.virol.2010. 07.027

Lefort, S., Soucy-Faulkner, A., Grandvaux, N., and Flamand, L. (2007). Binding of Kaposi's sarcoma-associated herpesvirus K-bZIP to interferon-responsive factor 3 elements modulates antiviral gene expression. J. Virol. 81, 10950-10960. doi: 10.1128/JVI.00183-07
Li, M., Lee, H., Yoon, D. W., Albrecht, J. C., Fleckenstein, B., Neipel, F., et al. (1997). Kaposi's sarcoma-associated herpesvirus encodes a functional cyclin. J. Virol. 71, 1984-1991.

Liang, C., Oh, B.-H., and Jung, J. U. (2015). Novel functions of viral anti-apoptotic factors. Nat. Rev. Microbiol. 13, 7-12. doi: 10.1038/nrmicro3369

Lim, C., Gwack, Y., Hwang, S., Kim, S., and Choe, J. (2001). The transcriptional activity of cAMP response element-binding protein-binding protein is modulated by the latency associated nuclear antigen of Kaposi's sarcoma-associated herpesvirus. J. Biol. Chem. 276, 31016-31022. doi: 10.1074/jbc.M102431200

Lin, J., Johannsen, E., Robertson, E., and Kieff, E. (2002). Epstein-Barr virus nuclear antigen $3 \mathrm{C}$ putative repression domain mediates coactivation of the LMP1 promoter with EBNA-2. J. Virol. 76, 232-242. doi: 10.1128/JVI.76.1.232242.2002

Lin, S. F., Robinson, D. R., Miller, G., and Kung, H. J. (1999). Kaposi's sarcomaassociated herpesvirus encodes a bZIP protein with homology to BZLF1 of Epstein-Barr virus. J. Virol. 73, 1909-1917.

Liu, J., Martin, H., Shamay, M., Woodard, C., Tang, Q. Q., and Hayward, S. D. (2007). Kaposi's sarcoma-associated herpesvirus LANA protein downregulates nuclear glycogen synthase kinase 3 activity and consequently blocks differentiation. J. Virol. 81, 4722-4731. doi: 10.1128/JVI. 02548-06

Liu, L., Eby, M. T., Rathore, N., Sinha, S. K., Kumar, A., and Chaudhary, P. M. (2002). The human herpes virus 8-encoded viral FLICE inhibitory protein physically associates with and persistently activates the Ikappa B kinase complex. J. Biol. Chem. 277, 13745-13751. doi: 10.1074/jbc. M110480200

Loo, D. T. (2011). In situ detection of apoptosis by the TUNEL assay: an overview of techniques. Methods Mol. Biol. 682, 3-13. doi: 10.1007/978-1-60327-409-8_1

Lopes, R. B., Gangeswaran, R., Mcneish, I. A., Wang, Y., and Lemoine, N. R. (2007). Expression of the IAP protein family is dysregulated in pancreatic cancer cells and is important for resistance to chemotherapy. Int. J. Cancer 120, 2344-2352. doi: $10.1002 /$ ijc. 22554

Lu, J., Jha, H. C., Verma, S. C., Sun, Z., Banerjee, S., Dzeng, R., et al. (2014). Kaposi's sarcoma-associated herpesvirus-encoded LANA contributes to viral latent replication by activating phosphorylation of survivin. J. Virol. 88, 42044217. doi: 10.1128/JVI.03855-13

Lu, J., Murakami, M., Verma, S. C., Cai, Q., Haldar, S., Kaul, R., et al. (2010). Epstein-Barr Virus nuclear antigen 1 (EBNA1) confers resistance to apoptosis in EBV-positive B-lymphoma cells through up-regulation of survivin. Virology 410, 64-75. doi: 10.1016/j.virol.2010.10.029

Lu, J. J., Chen, J. Y., Hsu, T. Y., Yu, W. C., Su, I. J., and Yang, C. S. (1996). Induction of apoptosis in epithelial cells by Epstein-Barr virus latent membrane protein 1. J. Gen. Virol. 77(Pt 8), 1883-1892. doi: 10.1099/0022-1317-77-8-1883

Lu, J. J., Chen, J. Y., Hsu, T. Y., Yu, W. C., Su, I. J., and Yang, C. S. (1997). Cooperative interaction between $\mathrm{Bcl}-2$ and Epstein-Barr virus latent membrane protein 1 in the growth transformation of human epithelial cells. J. Gen. Virol. 78(Pt 11), 2975-2985. doi: 10.1099/0022-1317-78-11-2975

Lukac, D. M., Garibyan, L., Kirshner, J. R., Palmeri, D., and Ganem, D. (2001). DNA binding by Kaposi's sarcoma-associated herpesvirus lytic switch protein is necessary for transcriptional activation of two viral delayed early promoters. J. Virol. 75, 6786-6799. doi: 10.1128/JVI.75.15.6786-6799.2001

Magrath, I. (1992). Molecular basis of lymphomagenesis. Cancer Res. 52, 5529s5540s.

Magrath, I., Jain, V., and Bhatia, K. (1992). Epstein-Barr virus and Burkitt's lymphoma. Semin. Cancer Biol. 3, 285-295.

Majno, G., and Joris, I. (1995). Apoptosis, oncosis, and necrosis. An overview of cell death. Am J Pathol 146, 3-15.

Mannick, J. B., Cohen, J. I., Birkenbach, M., Marchini, A., and Kieff, E. (1991). The Epstein-Barr virus nuclear protein encoded by the leader of the EBNA RNAs is important in B-lymphocyte transformation. J. Virol. 65, 6826-6837.

Mannick, J. B., Tong, X., Hemnes, A., and Kieff, E. (1995). The Epstein-Barr virus nuclear antigen leader protein associates with hsp72/hsc73. J. Virol. 69, 8169-8172.

Marin, M. C., Hsu, B., Stephens, L. C., Brisbay, S., and Mcdonnell, T. J. (1995). The functional basis of c-myc and bcl-2 complementation during multistep lymphomagenesis in vivo. Exp. Cell Res. 217, 240-247. doi: 10.1006/excr.1995.1083 
Marquitz, A. R., Mathur, A., Nam, C. S., and Raab-Traub, N. (2011). The EpsteinBarr Virus BART microRNAs target the pro-apoptotic protein Bim. Virology 412, 392-400. doi: 10.1016/j.virol.2011.01.028

Martin, S. J., and Green, D. R. (1995). Protease activation during apoptosis: death by a thousand cuts? Cell 82, 349-352. doi: 10.1016/0092-8674(95)90422-0

Maruo, S., Wu, Y., Ito, T., Kanda, T., Kieff, E. D., and Takada, K. (2009). Epstein-Barr virus nuclear protein EBNA3C residues critical for maintaining lymphoblastoid cell growth. Proc. Natl. Acad. Sci. U.S.A. 106, 4419-4424. doi: 10.1073/pnas.0813134106

Matta, H., Sun, Q., Moses, G., and Chaudhary, P. M. (2003). Molecular genetic analysis of human herpes virus 8-encoded viral FLICE inhibitory protein-induced NF-kappaB activation. J. Biol. Chem. 278, 52406-52411. doi: 10.1074/jbc.M307308200

Mazumder, E. D., Jardin, C., Vogel, B., Heck, E., Scholz, B., Lengenfelder, D., et al. (2012). A molecular model for the differential activation of STAT3 and STAT6 by the herpesviral oncoprotein tip. PLOS ONE 7:e34306. doi: 10.1371/journal.pone.0034306

McCarthy, N. J., and Evan, G. I. (1998). Methods for detecting and quantifying apoptosis. Curr. Top. Dev. Biol. 36, 259-278. doi: 10.1016/S00702153(08)60507-4

McLaughlin-Drubin, M. E., and Munger, K. (2008). Viruses associated with human cancer. Biochim. Biophys. Acta 1782, 127-150. doi: 10.1016/j.bbadis.2007.12.005

Min, C. K., Bang, S. Y., Cho, B. A., Choi, Y. H., Yang, J. S., Lee, S. H., et al. (2008). Role of amphipathic helix of a herpesviral protein in membrane deformation and T cell receptor downregulation. PLoS Pathog. 4:e1000209. doi: 10.1371/journal.ppat.1000209

Minn, A. J., Rudin, C. M., Boise, L. H., and Thompson, C. B. (1995). Expression of bcl-xL can confer a multidrug resistance phenotype. Blood 86, 1903-1910.

Minn, A. J., Velez, P., Schendel, S. L., Liang, H., Muchmore, S. W., Fesik, S. W., et al. (1997). Bcl-x(L) forms an ion channel in synthetic lipid membranes. Nature 385, 353-357. doi: 10.1038/385353a0

Miquel, C., Borrini, F., Grandjouan, S., Auperin, A., Viguier, J., Velasco, V., et al. (2005). Role of bax mutations in apoptosis in colorectal cancers with microsatellite instability. Am. J. Clin. Pathol. 123, 562-570. doi: 10.1309/JQ2X3RV3L8F9TGYW

Moore, P. S., Boshoff, C., Weiss, R. A., and Chang, Y. (1996). Molecular mimicry of human cytokine and cytokine response pathway genes by KSHV. Science 274, 1739-1744. doi: 10.1126/science.274.5293.1739

Morin, G., Robinson, B. A., Rogers, K. S., and Wong, S. W. (2015). A rhesus rhadinovirus viral interferon (IFN) regulatory factor is virion associated and inhibits the early IFN antiviral response. J. Virol. 89, 7707-7721. doi: 10.1128/JVI.01175-15

Mueller, N. (1991). An epidemiologist's view of the new molecular biology findings in Hodgkin's disease. Ann. Oncol. 2(Suppl. 2), 23-28. doi: 10.1007/978-1-48997305-4_3

Muralidhar, S., Pumfery, A. M., Hassani, M., Sadaie, M. R., Kishishita, M., Brady, J. N., et al. (1998). Identification of kaposin (open reading frame K12) as a human herpesvirus 8 (Kaposi's sarcoma-associated herpesvirus) transforming gene. J. Virol. 72, 4980-4988.

Nicholas, J., Ruvolo, V. R., Burns, W. H., Sandford, G., Wan, X., Ciufo, D., et al. (1997). Kaposi's sarcoma-associated human herpesvirus-8 encodes homologues of macrophage inflammatory protein-1 and interleukin-6. Nat. Med. 3, 287292. doi: 10.1038/nm0397-287

Nishimura, K., Ueda, K., Sakakibara, S., Do, E., Ohsaki, E., Okuno, T., et al. (2003). A viral transcriptional activator of Kaposi's sarcomaassociated herpesvirus (KSHV) induces apoptosis, which is blocked in KSHV-infected cells. Virology 316, 64-74. doi: 10.1016/S0042-6822(03) 00582-8

Noguchi, T., Ikeda, K., Yamamoto, K., Yoshida, I., Ashiba, A., Tsuchiyama, J., et al. (2001). Antisense oligodeoxynucleotides to latent membrane protein 1 induce growth inhibition, apoptosis and Bcl-2 suppression in Epstein-Barr virus (EBV)-transformed B-lymphoblastoid cells, but not in EBV-positive natural killer cell lymphoma cells. Br. J. Haematol. 114, 84-92. doi: 10.1046/j.13652141.2001.02887.x

Ojala, P. M., Tiainen, M., Salven, P., Veikkola, T., Castanos-Velez, E., Sarid, R., et al. (1999). Kaposi's sarcoma-associated herpesvirus-encoded v-cyclin triggers apoptosis in cells with high levels of cyclin-dependent kinase 6. Cancer Res. 59, 4984-4989.
Ojala, P. M., Yamamoto, K., Castanos-Velez, E., Biberfeld, P., Korsmeyer, S. J., and Makela, T. P. (2000). The apoptotic v-cyclin-CDK6 complex phosphorylates and inactivates Bcl-2. Nat. Cell Biol. 2, 819-825. doi: 10.1038/35041064

Oren, M., and Rotter, V. (1999). Introduction: p53-the first twenty years. Cell Mol. Life. Sci. 55, 9-11. doi: 10.1007/s000180050265

Orzechowska, B. U., Powers, M. F., Sprague, J., Li, H., Yen, B., Searles, R. P., et al. (2008). Rhesus macaque rhadinovirus-associated non-Hodgkin lymphoma: animal model for KSHV-associated malignancies. Blood 112, 4227-4234. doi: 10.1182/blood-2008-04-151498

Ozoren, N., and El-Deiry, W. S. (2003). Cell surface death receptor signaling in normal and cancer cells. Semin. Cancer Biol. 13, 135-147. doi: 10.1016/S1044579X(02)00131-1

Park, J., Cho, N. H., Choi, J. K., Feng, P., Choe, J., and Jung, J. U. (2003). Distinct roles of cellular Lck and p80 proteins in herpesvirus saimiri Tip function on lipid rafts. J. Virol. 77, 9041-9051. doi: 10.1128/JVI.77.16.9041-9051.2003

Park, J., Lee, B. S., Choi, J. K., Means, R. E., Choe, J., and Jung, J. U. (2002). Herpesviral protein targets a cellular WD repeat endosomal protein to downregulate T lymphocyte receptor expression. Immunity 17, 221-233. doi: 10.1016/S1074-7613(02)00368-0

Parravicini, C., Chandran, B., Corbellino, M., Berti, E., Paulli, M., Moore, P. S., et al. (2000). Differential viral protein expression in Kaposi's sarcomaassociated herpesvirus-infected diseases: Kaposi's sarcoma, primary effusion lymphoma, and multicentric Castleman's disease. Am. J. Pathol. 156, 743-749. doi: 10.1016/S0002-9440(10)64940-1

Paschos, K., Parker, G. A., Watanatanasup, E., White, R. E., and Allday, M. J. (2012). BIM promoter directly targeted by EBNA3C in polycomb-mediated repression by EBV. Nucleic Acids Res. 40, 7233-7246. doi: 10.1093/nar/gks391

Paschos, K., Smith, P., Anderton, E., Middeldorp, J. M., White, R. E., and Allday, M. J. (2009). Epstein-barr virus latency in B cells leads to epigenetic repression and CpG methylation of the tumour suppressor gene Bim. PLoS Pathog. 5:e1000492. doi: 10.1371/journal.ppat.1000492

Pegman, P. M., Smith, S. M., D’souza, B. N., Loughran, S. T., Maier, S., Kempkes, B., et al. (2006). Epstein-Barr virus nuclear antigen 2 trans-activates the cellular antiapoptotic bfl-1 gene by a CBF1/RBPJ kappa-dependent pathway. J. Virol. 80, 8133-8144. doi: 10.1128/JVI.00278-06

Pekkonen, P., Jarviluoma, A., Zinovkina, N., Cvrljevic, A., Prakash, S., Westermarck, J., et al. (2014). KSHV viral cyclin interferes with T-cell development and induces lymphoma through Cdk6 and Notch activation in vivo. Cell Cycle 13, 3670-3684. doi: 10.4161/15384101.2014.964118

Pennati, M., Folini, M., and Zaffaroni, N. (2007). Targeting survivin in cancer therapy: fulfilled promises and open questions. Carcinogenesis 28, 1133-1139. doi: 10.1093/carcin/bgm047

Pepper, C., Hoy, T., and Bentley, D. P. (1997). Bcl-2/Bax ratios in chronic lymphocytic leukaemia and their correlation with in vitro apoptosis and clinical resistance. Br. J. Cancer 76, 935-938. doi: 10.1038/bjc.1997.487

Pfeffer, S., Zavolan, M., Grasser, F. A., Chien, M., Russo, J. J., Ju, J., et al. (2004). Identification of virus-encoded microRNAs. Science 304, 734-736. doi: $10.1126 /$ science. 1096781

Plati, J., Bucur, O., and Khosravi-Far, R. (2011). Apoptotic cell signaling in cancer progression and therapy. Integr. Biol. (Camb.) 3, 279-296. doi: 10.1039/c0ib00144a

Platt, G. M., Simpson, G. R., Mittnacht, S., and Schulz, T. F. (1999). Latent nuclear antigen of Kaposi's sarcoma-associated herpesvirus interacts with RING3, a homolog of the Drosophila female sterile homeotic (fsh) gene. J. Virol. 73, 9789-9795.

Polizzotto, M. N., Uldrick, T. S., Hu, D., and Yarchoan, R. (2012). Clinical manifestations of kaposi sarcoma herpesvirus lytic activation: multicentric castleman disease (KSHV-MCD) and the KSHV inflammatory cytokine syndrome. Front. Microbiol. 3:73. doi: 10.3389/fmicb.2012. 00073

Polster, B. M., Pevsner, J., and Hardwick, J. M. (2004). Viral Bcl-2 homologs and their role in virus replication and associated diseases. Biochim. Biophys. Acta 1644, 211-227. doi: 10.1016/j.bbamcr.2003.11.001

Poole, L. J., Zong, J. C., Ciufo, D. M., Alcendor, D. J., Cannon, J. S., Ambinder, R., et al. (1999). Comparison of genetic variability at multiple loci across the genomes of the major subtypes of Kaposi's sarcoma-associated herpesvirus reveals evidence for recombination and for two distinct types of open reading frame K15 alleles at the right-hand end. J. Virol. 73, 6646-6660. 
Portis, T., and Longnecker, R. (2004). Epstein-Barr virus (EBV) LMP2A mediates B-lymphocyte survival through constitutive activation of the Ras/PI3K/Akt pathway. Oncogene 23, 8619-8628. doi: 10.1038/sj.onc.1207905

Prakash, O., Swamy, O. R., Peng, X., Tang, Z. Y., Li, L., Larson, J. E., et al. (2005). Activation of Src kinase Lyn by the Kaposi sarcoma-associated herpesvirus K1 protein: implications for lymphomagenesis. Blood 105, 3987-3994. doi: 10.1182/blood-2004-07-2781

Pratt, Z. L., Zhang, J., and Sugden, B. (2012). The latent membrane protein 1 (LMP1) oncogene of Epstein-Barr virus can simultaneously induce and inhibit apoptosis in B cells. J. Virol. 86, 4380-4393. doi: 10.1128/JVI.06966-11

Radkov, S. A., Kellam, P., and Boshoff, C. (2000). The latent nuclear antigen of Kaposi sarcoma-associated herpesvirus targets the retinoblastoma-E2F pathway and with the oncogene Hras transforms primary rat cells. Nat. Med. 6, 11211127. doi: $10.1038 / 80459$

Raffo, A. J., Perlman, H., Chen, M. W., Day, M. L., Streitman, J. S., and Buttyan, R. (1995). Overexpression of bcl-2 protects prostate cancer cells from apoptosis in vitro and confers resistance to androgen depletion in vivo. Cancer Res. 55, $4438-4445$.

Reed, J. C. (1997). Bcl-2 family proteins: regulators of apoptosis and chemoresistance in hematologic malignancies. Semin. Hematol. 34, 9-19.

Reesink-Peters, N., Hougardy, B. M., Van Den Heuvel, F. A., Ten Hoor, K. A., Hollema, H., Boezen, H. M., et al. (2005). Death receptors and ligands in cervical carcinogenesis: an immunohistochemical study. Gynecol. Oncol. 96, 705-713. doi: 10.1016/j.ygyno.2004.10.046

Reza, M. J., Kamble, A., Ahmad, M., Krishnasastry, M. V., and Sahu, A. (2013). Dissection of functional sites in herpesvirus saimiri complement control protein homolog. J. Virol. 87, 282-295. doi: 10.1128/JVI.01867-12

Ritthipichai, K., Nan, Y., Bossis, I., and Zhang, Y. (2012). Viral FLICE inhibitory protein of rhesus monkey rhadinovirus inhibits apoptosis by enhancing autophagosome formation. PLOS ONE 7:e39438. doi: 10.1371/journal.pone.0039438

Robinson, B. A., Estep, R. D., Messaoudi, I., Rogers, K. S., and Wong, S. W. (2012). Viral interferon regulatory factors decrease the induction of Type I and Type II interferon during rhesus macaque rhadinovirus infection. J. Virol. 86, 2197-2211. doi: 10.1128/JVI.05047-11

Rong, S., Wheeler, D., and Weber, F. (2014). Efficient Marek's disease virus (MDV) and herpesvirus of turkey infection of the QM7 cell line that does not contain latent MDV genome. Avian. Pathol. 43, 414-419. doi: 10.1080/03079457.2014.956687

Rossetto, C., Gao, Y., Yamboliev, I., Papouskova, I., and Pari, G. (2007). Transcriptional repression of K-Rta by Kaposi's sarcoma-associated herpesvirus K-bZIP is not required for oriLyt-dependent DNA replication. Virology 369, 340-350. doi: 10.1016/j.virol.2007.08.019

Rossetto, C. C., and Pari, G. S. (2014). PAN's Labyrinth: molecular biology of Kaposi's sarcoma-associated herpesvirus (KSHV) PAN RNA, a multifunctional long noncoding RNA. Viruses 6, 4212-4226. doi: 10.3390/ v6114212

Rymo, L. (1979). Identification of transcribed regions of Epstein-Barr virus DNA in Burkitt lymphoma-derived cells. J. Virol. 32, 8-18.

Sadagopan, S., Sharma-Walia, N., Veettil, M. V., Raghu, H., Sivakumar, R., Bottero, V., et al. (2007). Kaposi's sarcoma-associated herpesvirus induces sustained NF-kappaB activation during de novo infection of primary human dermal microvascular endothelial cells that is essential for viral gene expression. J. Virol. 81, 3949-3968. doi: 10.1128/JVI.02333-06

Sadler, R., Wu, L., Forghani, B., Renne, R., Zhong, W., Herndier, B., et al. (1999). A complex translational program generates multiple novel proteins from the latently expressed kaposin (K12) locus of Kaposi's sarcoma-associated herpesvirus. J. Virol. 73, 5722-5730.

Saha, A., Bamidele, A., Murakami, M., and Robertson, E. S. (2010a). EBNA3C attenuates the function of p53 through interaction with inhibitor of growth family proteins 4 and 5. J. Virol. 85, 2079-2088. doi: 10.1128/JVI.02279-10

Saha, A., Halder, S., Upadhyay, S. K., Lu, J., Kumar, P., Murakami, M., et al. (2011). Epstein-Barr virus nuclear antigen 3C facilitates G1-S transition by stabilizing and enhancing the function of cyclin D1. PLoS Pathog. 7:e1001275. doi: 10.1371/journal.ppat.1001275

Saha, A., Kaul, R., Murakami, M., and Robertson, E. S. (2010b). Tumor viruses and cancer biology: modulating signaling pathways for therapeutic intervention. Cancer Biol. Ther. 10, 961-978. doi: 10.4161/cbt.10.10.13923
Saha, A., Lu, J., Morizur, L., Upadhyay, S. K., Aj, M. P., and Robertson, E. S. (2012). E2F1 mediated apoptosis induced by the DNA damage response is blocked by EBV nuclear antigen 3C in lymphoblastoid cells. PLoS Pathog. 8:e1002573. doi: 10.1371/journal.ppat.1002573

Saha, A., Murakami, M., Kumar, P., Bajaj, B., Sims, K., and Robertson, E. S. (2009). Epstein-Barr virus nuclear antigen 3C augments Mdm2-mediated p53 ubiquitination and degradation by deubiquitinating Mdm2. J. Virol. 83, 46524669. doi: 10.1128/JVI.02408-08

Sahu, S. K., Mohanty, S., Kumar, A., Kundu, C. N., Verma, S. C., and Choudhuri, T. (2013). Epstein-Barr virus nuclear antigen 3C interact with p73: interplay between a viral oncoprotein and cellular tumor suppressor. Virology 448, 333-343. doi: 10.1016/j.virol.2013.10.023

Saraste, A., and Pulkki, K. (2000). Morphologic and biochemical hallmarks of apoptosis. Cardiovasc. Res. 45, 528-537. doi: 10.1016/S0008-6363(99)00384-3

Saridakis, V., Sheng, Y., Sarkari, F., Holowaty, M. N., Shire, K., Nguyen, T., et al. (2005). Structure of the p53 binding domain of HAUSP/USP7 bound to Epstein-Barr nuclear antigen 1 implications for EBV-mediated immortalization. Mol. Cell. 18, 25-36. doi: 10.1016/j.molcel.2005.02.029

Schneider, P., and Tschopp, J. (2000). Apoptosis induced by death receptors. Pharm. Acta Helv. 74, 281-286. doi: 10.1016/S0031-6865(99)00038-2

Searles, R. P., Bergquam, E. P., Axthelm, M. K., and Wong, S. W. (1999). Sequence and genomic analysis of a Rhesus macaque rhadinovirus with similarity to Kaposi's sarcoma-associated herpesvirus/human herpesvirus 8. J. Virol. 73, 3040-3053.

Seo, T., Park, J., and Choe, J. (2005). Kaposi's sarcoma-associated herpesvirus viral IFN regulatory factor 1 inhibits transforming growth factor-beta signaling. Cancer Res. 65, 1738-1747. doi: 10.1158/0008-5472.CAN-04-2374

Sharp, T. V., Wang, H. W., Koumi, A., Hollyman, D., Endo, Y., Ye, H., et al. (2002). K15 protein of Kaposi's sarcoma-associated herpesvirus is latently expressed and binds to HAX-1, a protein with antiapoptotic function. J. Virol. 76, 802-816. doi: 10.1128/JVI.76.2.802-816.2002

Shen, X. G., Wang, C., Li, Y., Wang, L., Zhou, B., Xu, B., et al. (2010). Downregulation of caspase-9 is a frequent event in patients with stage II colorectal cancer and correlates with poor clinical outcome. Colorectal Dis. 12, 1213-1218. doi: 10.1111/j.1463-1318.2009.02009.x

Sherr, C. J., and McCormick, F. (2002). The RB and p53 pathways in cancer. Cancer Cell 2, 103-112. doi: 10.1016/S1535-6108(02)00102-2

Shin, Y. C., Nakamura, H., Liang, X., Feng, P., Chang, H., Kowalik, T. F., et al. (2006). Inhibition of the ATM/p53 signal transduction pathway by Kaposi's sarcoma-associated herpesvirus interferon regulatory factor 1. J. Virol. 80, 2257-2266. doi: 10.1128/JVI.80.5.2257-2266.2006

Si, H., and Robertson, E. S. (2006). Kaposi's sarcoma-associated herpesvirusencoded latency-associated nuclear antigen induces chromosomal instability through inhibition of p53 function. J. Virol. 80, 697-709. doi: 10.1128/JVI.80.2.697-709.2006

Singh, A. K., Mullick, J., Bernet, J., and Sahu, A. (2006). Functional characterization of the complement control protein homolog of herpesvirus saimiri: ARG-118 is critical for factor I cofactor activities. J. Biol. Chem. 281, 23119-23128. doi: 10.1074/jbc.M603085200

Slatter, T. L., Hung, N., Campbell, H., Rubio, C., Mehta, R., Renshaw, P., et al. (2011). Hyperproliferation, cancer, and inflammation in mice expressing a Delta133p53-like isoform. Blood 117, 5166-5177. doi: 10.1182/blood-2010-11321851

Small, S., Keerthivasan, G., Huang, Z., Gurbuxani, S., and Crispino, J. D. (2010). Overexpression of survivin initiates hematologic malignancies in vivo. Leukemia 24, 1920-1926. doi: 10.1038/leu.2010.198

Song, M. J., Deng, H., and Sun, R. (2003). Comparative study of regulation of RTA-responsive genes in Kaposi's sarcoma-associated herpesvirus/human herpesvirus 8. J. Virol. 77, 9451-9462. doi: 10.1128/JVI.77.17.9451-9462.2003

Soulier, J., Grollet, L., Oksenhendler, E., Cacoub, P., Cazals-Hatem, D., Babinet, P., et al. (1995). Kaposi's sarcoma-associated herpesvirus-like DNA sequences in multicentric Castleman's disease. Blood 86, 1276-1280.

Steelman, L. S., Pohnert, S. C., Shelton, J. G., Franklin, R. A., Bertrand, F. E., and Mccubrey, J. A. (2004). JAK/STAT, Raf/MEK/ERK, PI3K/Akt and BCR$\mathrm{ABL}$ in cell cycle progression and leukemogenesis. Leukemia 18, 189-218. doi: 10.1038/sj.leu.2403241

Steinbruck, L., Gustems, M., Medele, S., Schulz, T. F., Lutter, D., and Hammerschmidt, W. (2015). K1 and K15 of Kaposis sarcoma-associated 
herpesvirus are partial functional homologues of latent membrane protein $2 \mathrm{~A}$ of Epstein-Barr Virus. J. Virol. 89, 7248-7261. doi: 10.1128/JVI.00839-15

Stine, J. T., Wood, C., Hill, M., Epp, A., Raport, C. J., Schweickart, V. L., et al. (2000). KSHV-encoded CC chemokine vMIP-III is a CCR4 agonist, stimulates angiogenesis, and selectively chemoattracts TH2 cells. Blood 95, 1151-1157.

Sun, R., Lin, S. F., Gradoville, L., Yuan, Y., Zhu, F., and Miller, G. (1998). A viral gene that activates lytic cycle expression of Kaposi's sarcomaassociated herpesvirus. Proc. Natl. Acad. Sci. U.S.A. 95, 10866-10871. doi: 10.1073/pnas.95.18.10866

Sun, R., Lin, S. F., Staskus, K., Gradoville, L., Grogan, E., Haase, A., et al. (1999). Kinetics of Kaposi's sarcoma-associated herpesvirus gene expression. J. Virol. $73,2232-2242$.

Sun, Z., Xiao, B., Jha, H. C., Lu, J., Banerjee, S., and Robertson, E. S. (2014). Kaposi's sarcoma-associated herpesvirus-encoded LANA can induce chromosomal instability through targeted degradation of the mitotic checkpoint kinase Bub1. J. Virol. 88, 7367-7378. doi: 10.1128/JVI.00554-14

Swanson-Mungerson, M., Bultema, R., and Longnecker, R. (2010). Epstein-Barr virus LMP2A imposes sensitivity to apoptosis. J. Gen. Virol. 91, 2197-2202. doi: 10.1099/vir.0.021444-0

Szegezdi, E., Fitzgerald, U., and Samali, A. (2003). Caspase-12 and ER-stressmediated apoptosis: the story so far. Ann. N. Y. Acad. Sci. 1010, 186-194. doi: 10.1196/annals. 1299.032

Szekely, L., Selivanova, G., Magnusson, K. P., Klein, G., and Wiman, K. G. (1993). EBNA-5, an Epstein-Barr virus-encoded nuclear antigen, binds to the retinoblastoma and p53 proteins. Proc. Natl. Acad. Sci. U.S.A. 90, 5455-5459. doi: $10.1073 /$ pnas. 90.12 .5455

Thakker, S., Purushothaman, P., Gupta, N., Challa, S., Cai, Q., and Verma, S. C. (2015). Kaposi's sarcoma-associated herpesvirus latency-associated nuclear antigen inhibits major histocompatibility complex Class II expression by disrupting enhanceosome assembly through binding with the regulatory factor X complex. J. Virol. 89, 5536-5556. doi: 10.1128/JVI. 03713-14

Thome, M., Schneider, P., Hofmann, K., Fickenscher, H., Meinl, E., Neipel, F., et al. (1997). Viral FLICE-inhibitory proteins (FLIPs) prevent apoptosis induced by death receptors. Nature 386, 517-521. doi: 10.1038/ $386517 \mathrm{a} 0$

Thorley-Lawson, D. A., and Gross, A. (2004). Persistence of the Epstein-Barr virus and the origins of associated lymphomas. N. Engl. J. Med. 350, 1328-1337. doi: 10.1056/NEJMra032015

Tibbetts, M. D., Zheng, L., and Lenardo, M. J. (2003). The death effector domain protein family: regulators of cellular homeostasis. Nat. Immunol. 4, 404-409. doi: $10.1038 /$ ni0503-404

Tomkinson, B., Robertson, E., and Kieff, E. (1993). Epstein-Barr virus nuclear proteins EBNA-3A and EBNA-3C are essential for B-lymphocyte growth transformation. J. Virol. 67, 2014-2025.

Tomlinson, C. C., and Damania, B. (2004). The K1 protein of Kaposi's sarcomaassociated herpesvirus activates the Akt signaling pathway. J. Virol. 78, 19181927. doi: 10.1128/JVI.78.4.1918-1927.2004

Tsujimoto, Y., Finger, L. R., Yunis, J., Nowell, P. C., and Croce, C. M. (1984). Cloning of the chromosome breakpoint of neoplastic B cells with the $t(14 ; 18)$ chromosome translocation. Science 226, 1097-1099. doi: $10.1126 /$ science. 6093263

Ueda, K., Ishikawa, K., Nishimura, K., Sakakibara, S., Do, E., and Yamanishi, K. (2002). Kaposi's sarcoma-associated herpesvirus (human herpesvirus 8) replication and transcription factor activates the K9 (vIRF) gene through two distinct cis elements by a non-DNA-binding mechanism. J. Virol. 76, 1204412054. doi: 10.1128/JVI.76.23.12044-12054.2002

Uldrick, T. S., Wang, V., O'mahony, D., Aleman, K., Wyvill, K. M., Marshall, V., et al. (2010). An interleukin-6-related systemic inflammatory syndrome in patients co-infected with Kaposi sarcoma-associated herpesvirus and HIV but without Multicentric Castleman disease. Clin. Infect. Dis 51, 350-358. doi: $10.1086 / 654798$

Uppal, T., Banerjee, S., Sun, Z., Verma, S. C., and Robertson, E. S. (2014). KSHV LANA-the master regulator of KSHV latency. Viruses 6, 4961-4998. doi: $10.3390 / \mathrm{v} 6124961$

Vaux, D. L., and Silke, J. (2003). Mammalian mitochondrial IAP binding proteins. Biochem. Biophys. Res. Commun. 304, 499-504. doi: 10.1016/S0006291X(03)00622-3
Verma, S. C., Lan, K., and Robertson, E. (2007). Structure and function of latencyassociated nuclear antigen. Curr. Top. Microbiol. Immunol. 312, 101-136. doi: 10.1007/978-3-540-34344-8_4

Verschuren, E. W., Klefstrom, J., Evan, G. I., and Jones, N. (2002). The oncogenic potential of Kaposi's sarcoma-associated herpesvirus cyclin is exposed by p53 loss in vitro and in vivo. Cancer Cell 2, 229-241. doi: 10.1016/S15356108(02)00123-X

Vikhanskaya, F., Lee, M. K., Mazzoletti, M., Broggini, M., and Sabapathy, K. (2007). Cancer-derived p53 mutants suppress p53-target gene expressionpotential mechanism for gain of function of mutant p53. Nucleic Acids Res. 35, 2093-2104. doi: 10.1093/nar/gkm099

Wang, J. J., Li, Y. F., Jin, Y. Y., Wang, X., and Chen, T. X. (2012). Effects of Epstein-Barr virus on the development of dendritic cells derived from cord blood monocytes: an essential role for apoptosis. Braz. J. Infect. Dis. 16, 19-26. doi: 10.1016/S1413-8670(12)70269-6

Wang, L., Brinkmann, M. M., Pietrek, M., Ottinger, M., DittrichBreiholz, O., Kracht, M., et al. (2007). Functional characterization of the M-type K15-encoded membrane protein of Kaposi's sarcomaassociated herpesvirus. J. Gen. Virol. 88, 1698-1707. doi: 10.1099/vir.0. 82807-0

Wang, L., Dittmer, D. P., Tomlinson, C. C., Fakhari, F. D., and Damania, B. (2006). Immortalization of primary endothelial cells by the K1 protein of Kaposi's sarcoma-associated herpesvirus. Cancer Res. 66, 3658-3666. doi: 10.1158/00085472.CAN-05-3680

Wang, S. E., Wu, F. Y., Fujimuro, M., Zong, J., Hayward, S. D., and Hayward, G. S. (2003). Role of CCAAT/enhancer-binding protein alpha (C/EBPalpha) in activation of the Kaposi's sarcoma-associated herpesvirus (KSHV) lytic-cycle replication-associated protein (RAP) promoter in cooperation with the KSHV replication and transcription activator (RTA) and RAP. J. Virol. 77, 600-623. doi: 10.1128/JVI.77.1.600-623.2003

Wang, Y., Sathish, N., Hollow, C., and Yuan, Y. (2011). Functional characterization of Kaposi's sarcoma-associated herpesvirus open reading frame K8 by bacterial artificial chromosome-based mutagenesis. J. Virol. 85, 1943-1957. doi: 10.1128/JVI.02060-10

Watanabe, T., Sugaya, M., Atkins, A. M., Aquilino, E. A., Yang, A., Borris, D. L., et al. (2003). Kaposi's sarcoma-associated herpesvirus latency-associated nuclear antigen prolongs the life span of primary human umbilical vein endothelial cells. J. Virol. 77, 6188-6196. doi: 10.1128/JVI.77.11.6188-6196.2003

Wen, K. W., and Damania, B. (2010). Hsp90 and Hsp40/Erdj3 are required for the expression and anti-apoptotic function of KSHV K1. Oncogene 29, 3532-3544. doi: $10.1038 /$ onc. 2010.124

White, R. E., Ramer, P. C., Naresh, K. N., Meixlsperger, S., Pinaud, L., Rooney, C., et al. (2012). EBNA3B-deficient EBV promotes B cell lymphomagenesis in humanized mice and is found in human tumors. J. Clin. Invest. 122, 1487-1502. doi: 10.1172/JCI58092

Wies, E., Hahn, A. S., Schmidt, K., Viebahn, C., Rohland, N., Lux, A., et al. (2009). The Kaposi's sarcoma-associated Herpesvirus-encoded vIRF-3 inhibits cellular IRF-5. J. Biol. Chem. 284, 8525-8538. doi: 10.1074/jbc.M809252200

Wies, E., Mori, Y., Hahn, A., Kremmer, E., Sturzl, M., Fleckenstein, B., et al. (2008). The viral interferon-regulatory factor-3 is required for the survival of KSHV-infected primary effusion lymphoma cells. Blood 111, 320-327. doi: 10.1182/blood-2007-05-092288

Wong, E. L., and Damania, B. (2006). Transcriptional regulation of the Kaposi's sarcoma-associated Herpesvirus K15 Gene. J. Virol. 80, 1385-1392. doi: 10.1128/JVI.80.3.1385-1392.2006

Wong, H. L., Wang, X., Chang, R. C., Jin, D. Y., Feng, H., Wang, Q., et al. (2005). Stable expression of EBERs in immortalized nasopharyngeal epithelial cells confers resistance to apoptotic stress. Mol. Carcinog. 44, 92-101. doi: $10.1002 / \mathrm{mc} .20133$

Wong, R. S. (2011). Apoptosis in cancer: from pathogenesis to treatment. J. Exp. Clin. Cancer Res. 30, 87. doi: 10.1186/1756-9966-30-87

Wong, S. W., Bergquam, E. P., Swanson, R. M., Lee, F. W., Shiigi, S. M., Avery, N. A., et al. (1999). Induction of B cell hyperplasia in simian immunodeficiency virus-infected rhesus macaques with the simian homologue of Kaposi's sarcoma-associated herpesvirus. J. Exp. Med. 190, 827-840. doi: 10.1084/jem.190.6.827

Wood, V. H., O'neil, J. D., Wei, W., Stewart, S. E., Dawson, C. W., and Young, L. S. (2007). Epstein-Barr virus-encoded EBNA1 regulates cellular gene transcription 
and modulates the STAT1 and TGFbeta signaling pathways. Oncogene 26, 4135-4147. doi: 10.1038/sj.onc. 1210496

Xu, S., Xue, C., Li, J., Bi, Y., and Cao, Y. (2011). Marek's disease virus type 1 microRNA miR-M3 suppresses cisplatin-induced apoptosis by targeting Smad2 of the transforming growth factor beta signal pathway. J. Virol. 85, 276-285. doi: 10.1128/JVI.01392-10

Xu, Y., Aucoin, D. P., Huete, A. R., Cei, S. A., Hanson, L. J., and Pari, G. S. (2005). A Kaposi's sarcoma-associated herpesvirus/human herpesvirus 8 ORF50 deletion mutant is defective for reactivation of latent virus and DNA replication. J. Virol. 79, 3479-3487. doi: 10.1128/JVI.79.6.3479-3487.2005

Yajima, M., Imadome, K., Nakagawa, A., Watanabe, S., Terashima, K., Nakamura, H., et al. (2008). A new humanized mouse model of EpsteinBarr virus infection that reproduces persistent infection, lymphoproliferative disorder, and cell-mediated and humoral immune responses. J. Infect. Dis. 198, 673-682. doi: 10.1086/590502

Yamamoto, N., Takizawa, T., Iwanaga, Y., and Shimizu, N. (2000). Malignant transformation of B lymphoma cell line BJAB by Epstein-Barr virus-encoded small RNAs. FEBS Lett. 484, 153-158. doi: 10.1016/S0014-5793(00)02145-1

Yang, A., Kaghad, M., Wang, Y., Gillett, E., Fleming, M. D., Dotsch, V., et al. (1998). p63, a p53 homolog at 3q27-29, encodes multiple products with transactivating, death-inducing, and dominant-negative activities. Mol. Cell. 2, 305-316. doi: 10.1016/S1097-2765(00)80275-0

Yang, Z., Yan, Z., and Wood, C. (2008). Kaposi's sarcoma-associated herpesvirus transactivator RTA promotes degradation of the repressors to regulate viral lytic replication. J. Virol. 82, 3590-3603. doi: 10.1128/JVI.02229-07

Yao, Z., Fanslow, W. C., Seldin, M. F., Rousseau, A. M., Painter, S. L., Comeau, M. R., et al. (1995). Herpesvirus Saimiri encodes a new cytokine, IL-17, which binds to a novel cytokine receptor. Immunity 3, 811-821. doi: 10.1016/10747613(95)90070-5

Yi, F., Saha, A., Murakami, M., Kumar, P., Knight, J. S., Cai, Q., et al. (2009). Epstein-Barr virus nuclear antigen 3C targets p53 and modulates its transcriptional and apoptotic activities. Virology 388, 236-247. doi: 10.1016/j.virol.2009.03.027

Yin, Q., Mcbride, J., Fewell, C., Lacey, M., Wang, X., Lin, Z., et al. (2008). MicroRNA-155 is an Epstein-Barr virus-induced gene that modulates EpsteinBarr virus-regulated gene expression pathways. J. Virol. 82, 5295-5306. doi: 10.1128/JVI.02380-07

Yoo, J., Kang, J., Lee, H. N., Aguilar, B., Kafka, D., Lee, S., et al. (2010). Kaposin$\mathrm{B}$ enhances the PROX1 mRNA stability during lymphatic reprogramming of vascular endothelial cells by Kaposi's sarcoma herpes virus. PLoS Pathog. 6:e1001046. doi: 10.1371/journal.ppat.1001046

Young, L. S., Dawson, C. W., and Eliopoulos, A. G. (1997). Viruses and apoptosis. Br. Med. Bull. 53, 509-521. doi: 10.1093/oxfordjournals.bmb.a011627

Zaldumbide, A., Ossevoort, M., Wiertz, E. J., and Hoeben, R. C. (2007). In cis inhibition of antigen processing by the latency-associated nuclear antigen I of Kaposi sarcoma herpes virus. Mol. Immunol. 44, 1352-1360. doi: 10.1016/j.molimm.2006.05.012

Zhang, X. N., and Huang, P. C. (2009). Cell survival and death program modulated by LMP1: implication in antitumor immunity. Ai Zheng 28, 831-837. doi: $10.5732 /$ cjc. 009.10077

Conflict of Interest Statement: The authors declare that the research was conducted in the absence of any commercial or financial relationships that could be construed as a potential conflict of interest.

Copyright (C) 2016 Banerjee, Uppal, Strahan, Dabral and Verma. This is an openaccess article distributed under the terms of the Creative Commons Attribution License (CC BY). The use, distribution or reproduction in other forums is permitted, provided the original author(s) or licensor are credited and that the original publication in this journal is cited, in accordance with accepted academic practice. No use, distribution or reproduction is permitted which does not comply with these terms. 